\title{
Continuous secondary-ice production initiated by updrafts through the melting layer in mountainous regions
}

\author{
Annika Lauber ${ }^{1}$, Jan Henneberger ${ }^{1}$, Claudia Mignani ${ }^{2}$, Fabiola Ramelli ${ }^{1}$, Julie T. Pasquier ${ }^{1}$, Jörg Wieder $^{1}$, \\ Maxime Hervo $^{3}$, and Ulrike Lohmann ${ }^{1}$ \\ ${ }^{1}$ ETH Zurich, Institute for Atmospheric and Climate Science, Zurich, Switzerland \\ ${ }^{2}$ Department of Environmental Sciences, University of Basel, Basel, Switzerland \\ ${ }^{3}$ Federal Office of Meteorology and Climatology MeteoSwiss, Payerne, Switzerland
}

Correspondence: Annika Lauber (annika.lauber@env.ethz.ch) and Jan Henneberger (jan.henneberger@env.ethz.ch)

Received: 22 September 2020 - Discussion started: 13 October 2020

Revised: 29 January 2021 - Accepted: 2 February 2021 - Published: 15 March 2021

\begin{abstract}
An accurate prediction of the ice crystal number concentration in clouds is important to determine the radiation budget, the lifetime, and the precipitation formation of clouds. Secondary-ice production is thought to be responsible for the observed discrepancies between the ice crystal number concentration and the ice-nucleating particle concentration in clouds. The Hallett-Mossop process is active between -3 and $-8^{\circ} \mathrm{C}$ and has been implemented into several models, while all other secondary-ice processes are poorly constrained and lack a well-founded quantification. During $2 \mathrm{~h}$ of measurements taken on a mountain slope just above the melting layer at temperatures warmer than $-3^{\circ} \mathrm{C}$, a continuously high concentration of small plates identified as secondary ice was observed. The presence of drizzle drops suggests droplet fragmentation upon freezing as the responsible secondary-ice mechanism. The constant supply of drizzle drops can be explained by a recirculation theory, suggesting that melted snowflakes, which sedimented through the melting layer, were reintroduced into the cloud as drizzle drops by orographically forced updrafts. Here we introduce a parametrization of droplet fragmentation at slightly sub-zero temperatures, where primary-ice nucleation is basically absent, and the first ice is initiated by the collision of drizzle drops with aged ice crystals sedimenting from higher altitudes. Based on previous measurements, we estimate that a droplet of $200 \mu \mathrm{m}$ in diameter produces 18 secondary-ice crystals when it fragments upon freezing. The application of the parametrization to our measurements suggests that the actual number of splinters produced by a fragmenting droplet may be up to an order of magnitude higher.
\end{abstract}

\section{Introduction}

Accurate weather forecasting in mountainous regions is more challenging than over flat topography as orography has a strong influence on the local weather; e.g., it creates local up- and downdrafts, which strongly impacts the development of clouds (Roe, 2005; Henneberg et al., 2017). Yet, orography is not very well resolved in numerical weather prediction models because the high resolution needed requires a lot of computational power that is often not available (e.g., Fundel et al., 2010; Gowan et al., 2018). Furthermore, microphysical processes in clouds, which affect the development of the concentration and size of ice crystals and cloud droplets, are still not completely understood (e.g., Field et al., 2017). However, the correct phase partitioning and concentration of cloud particles is important for the determination of the radiation budget, the lifetime, and the precipitation amount of clouds (e.g., Lohmann, 2002; Henneberg et al., 2017). This can be especially important for mixed-phase clouds (MPCs) consisting of ice crystals and liquid droplets since they have a major contribution to the total precipitation in the midlatitudes (Mülmenstädt et al., 2015).

MPCs are thermodynamically unstable because the saturation water vapor pressure over ice is lower than over liquid water, allowing ice crystals to grow faster than liquid droplets. The particle growth reduces the water vapor pressure and eventually leads to the evaporation of cloud droplets when the water vapor pressure drops below water vapor saturation over liquid. This process is called the Wegener-Bergeron-Findeisen process (Wegener, 1911; 
Bergeron, 1935; Findeisen, 1938) and can lead to rapid glaciation of clouds. Nevertheless, persistent MPCs have been frequently observed in mountainous regions, where the local topography produces sufficiently large updrafts to sustain a continuous condensate production (e.g., Korolev, 2007; Lohmann et al., 2016). An updraft velocity of about $2 \mathrm{~m} \mathrm{~s}^{-1}$ is often sufficient to maintain supersaturation with respect to water, which enables a simultaneous growth of cloud droplets and ice crystals (Korolev, 2007).

MPCs can exist between 0 and $-38^{\circ} \mathrm{C}$. In this temperature range, ice-nucleating particles (INPs) are required for cloud droplets to freeze. The resulting so-called primary ice can create additional ice crystals (secondary ice), which again can fragment and produce more secondary ice by any kind of fragmentation, referred to as secondary-ice production (SIP) (e.g., Field et al., 2017). Assuming only primary ice to exist, one would expect that the ice crystal number concentration (ICNC) equals the activated ice-nucleating-particle concentration (INPC) in clouds. This is observed for example in shallow stratocumulus (Mossop et al., 1972) or thin stratus clouds but often does not hold true in more convective clouds. A discrepancy between the INPC and the ICNC of up to 4 orders of magnitude has been observed in several studies (e.g., Koenig, 1963; Hobbs and Rangno, 1985; Crawford et al., 2012; Lasher-Trapp et al., 2016; Ladino et al., 2017; Beck et al., 2018). If surface-based processes like blowing snow (e.g., Beck et al., 2018) and the seeder-feeder process (hydrometeors which formed aloft precipitate into the cloud below; e.g., Bader and Roach, 1977; Ramelli et al., 2020a) can be excluded as a potential ice source, this discrepancy can only be explained by SIP.

On 22 February 2019, during the RACLETS (Role of Aerosols and CLouds Enhanced by Topography on Snow) campaign taking place in the region of Davos in the Swiss Alps (Mignani et al., 2021; Ramelli et al., 2020b, a; Georgakaki et al., 2020), a discrepancy between the INPC and ICNC of several orders of magnitude was measured. In the following subsection different SIP mechanisms, which might be responsible for this high discrepancy, are described. Furthermore, a recirculation theory by Korolev et al. (2020) is introduced in Sect. 1.2, which can explain the observations.

\subsection{Secondary-ice production mechanisms}

Six SIP mechanisms have been discussed over the past decades. They are expected to be active depending on the environmental conditions like temperature, cloud particle size distribution, and updrafts: (i) the rime-splintering or Hallett-Mossop process, (ii) collisional breakup, (iii) droplet fragmentation upon freezing, (iv) thermal-shock fragmentation, (v) fragmentation of sublimating or melting ice, and (vi) activation of INPs in transient supersaturation of freezing droplets (Korolev and Leisner, 2020).

The rime-splintering process describes the production of secondary ice during riming. Yet, the underlying physical mechanism of this process is not well defined (Field et al., 2017). The most common explanation for SIP during riming is that droplets, which freeze on an ice crystal, build up an internal pressure and break up upon freezing. In a laboratory study, Hallett and Mossop (1974) observed that rimesplintering is active at temperatures between -3 and $-8^{\circ} \mathrm{C}$ when particles grow by riming. Dong and Hallett (1989) showed that at temperatures above $-3^{\circ} \mathrm{C}$, droplets spread out on the ice surface and do not build an ice shell, while at temperatures below $-8^{\circ} \mathrm{C}$ the ice shell of rime might be too strong to break (Griggs and Choularton, 1983). While several observations of secondary ice could be explained by the rime-splintering process (e.g., Ono, 1971, 1972; HarrisHobbs and Cooper, 1987; Bower et al., 1996), secondary ice was also observed in cases where these requirements were not fulfilled (e.g., Korolev et al., 2020), or the SIP by rimesplintering alone was expected to be too slow to explain the observed rapid glaciation (e.g., Hobbs and Rangno, 1990).

Collisional breakup describes the break-up of an ice crystal due to a collision with another ice crystal. This process was shown to be active when large ice crystals (e.g., graupel or aggregates) are present (Korolev and Leisner, 2020). Fragments of ice crystals were observed in several field studies (e.g., Jiusto and Weickmann, 1973; Schwarzenboeck et al., 2009). Vardiman (1978) found that significant SIP occurs by collisional breakup when relatively large concentrations of rimed ice crystals are present in convective clouds. He concluded that collisional breakup cannot explain high secondary ICNCs at warm temperatures. The laboratory study of Takahashi et al. (1995) showed that a maximum SIP rate occurs at $-16^{\circ} \mathrm{C}$ when ice spheres with different growth modes collide.

Droplet fragmentation during freezing can happen when liquid water gets trapped inside a freezing droplet after an ice shell formed around the droplet and expands. Due to the lower density of ice than liquid water, an internal pressure builds up. If the pressure reaches a critical point, different processes have been observed to release the pressure: a complete breakup in mainly two halves; opening and closing of cracks; bubbles forming and bursting on the ice shell; and streams being ejected from the shell, which may contain small ice fragments (Lauber et al., 2018). An average number of splinters being ejected per freezing droplet could not be quantified so far because many ejected splinters are expected to be too small, and the processes happen so fast that the used measurement techniques until today were not able to detect all splinters (Lauber et al., 2018; Keinert et al., 2020). Keinert et al. (2020) showed that droplets freezing in moving air break up 1 order of magnitude more frequently than droplets freezing in stagnant air. Therefore, high wind speed and turbulence can be expected to increase the likelihood of droplet fragmentation. The highest fragmentation rate was observed around $-15^{\circ} \mathrm{C}$. It decreases to higher and lower temperatures, while it seems to increase again at temperatures close to $0^{\circ} \mathrm{C}$ (Keinert et al., 2020). The larger the droplet, the more 
likely it will fragment and the more splinters it will likely produce (Kolomeychuk et al., 1975; Lauber et al., 2018). Many field studies showed that large droplets are present in clouds before ICNCs exceed the INPCs by orders of magnitude (e.g., Koenig, 1963; Braham, 1964; Mossop et al., 1970; Hobbs and Rangno, 1990; Rangno, 2008; Lawson et al., 2017; Korolev et al., 2020) and often explained these observations with SIP by droplet fragmentation. Even though large droplets are rare in clouds, they might start a cascading process of splinter production when produced splinters hit other droplets, which subsequently freeze and produce more splinters (Koenig, 1963; Chisnell and Latham, 1974; Lawson et al., 2015).

Thermal-shock fragmentation (King and Fletcher, 1976) and the activation of INPs in transient supersaturation of freezing droplets both require precipitation-sized droplets to be active, while the fragmentation of sublimating ice can be important if cloud regions are affected by entrainment of dry air (Korolev and Leisner, 2020). Oraltay and Hallett (1989) observed no sublimation breakup for columnar and plate-like crystals, while breakup during melting only took place at relative humidities below $90 \%$.

From the six SIP mechanisms, the rime-splintering process is the best-constrained mechanism and has been implemented in some cloud microphysics schemes (e.g., Scott and Hobbs, 1977; Beheng, 1987; Phillips et al., 2001). There have been fewer attempts to include collisional breakup (e.g., Yano and Phillips, 2011; Phillips et al., 2017; Sotiropoulou et al., 2020a, 2021) and droplet fragmentation (e.g., Lawson et al., 2015; Yang et al., 2020). Sullivan et al. (2018b) modeled all three ice multiplication processes and showed that none of the three SIP mechanisms dominates the ICNC enhancement. While collisional breakup is important when low updrafts prevail, and high nucleation rates are present, droplet fragmentation and the rime-splintering process can also be important in INP-limited regions. However, they pointed out that the processes are not very well constrained by laboratory and in situ data.

\subsection{Persistent SIP immediately above the melting layer}

A remarkable finding of the study by Korolev et al. (2020) is the observation of small pristine ice crystals persisting immediately above the melting layer in clouds. They calculated a spatial correlation time $\tau_{\text {corr }}$ during which the environmental changes (e.g., air temperature, humidity, and cloud particle number concentration) are insignificant, and the shapes of the ice crystals can still be associated with the environment they are growing in. Based on their estimation, $\tau_{\text {corr }}$ is on the order of 60-120 s. Assuming water vapor saturation over liquid, an ice column at temperatures below $-3{ }^{\circ} \mathrm{C}$ can reach a length between 50 and $150 \mu \mathrm{m}$ during $\tau_{\text {corr }}$ depending on its aspect ratio. A relative humidity close to water saturation is a valid assumption in MPCs (Korolev and Isaac, 2006). It can be concluded that if external processes like blowing snow or the seeder-feeder process can be excluded, the discrepancy between the INPC and the concentration of columns shorter than 50 to $150 \mu \mathrm{m}$ in MPCs must emerge from SIP.

Korolev et al. (2020) suggested a recirculation process through the melting layer to be a possible explanation for the observed high concentration of small pristine ice crystals. Large ice crystals which fall through the melting layer as precipitation melt into drizzle-sized droplets. If convection or turbulence causes large updrafts, these droplets can be reintroduced into the cloud. Whenever these droplets freeze by the collision with ice crystals, the droplet-fragmentationupon-freezing process can become active and produce high numbers of secondary-ice particles.

\section{Experimental setup}

\subsection{RACLETS campaign}

The measurements used in this study were collected during the RACLETS campaign, which took place in February and March 2019 in the region of Davos in the Swiss Alps. The objective of this campaign was to improve the understanding of the influence of topography and aerosols on the development of clouds. For this goal, a set of instruments were deployed at different locations. Figure 1 shows the locations and instruments which were used for the analysis of the presented case study.

Measurements of the in-cloud properties such as the cloud particle concentration as well as their size distribution and shape were taken from the HoloGondel platform (Beck et al., 2017) on the Gotschnabahn, which is described in more detail in Sect. 2.2. As part of the MeteoSwiss observation network, a ceilometer (Vaisala, Model CL31) was installed in Klosters $(1200 \mathrm{~m})$ to determine the cloud base height (Hervo, 2020a) as well as a wind profiler (Vaisala, Model Lap3000, Finland) in Wolfgang to measure the horizontal wind field (Hervo, 2020b). The general wind pattern on the ground was determined by data from different MeteoSwiss stations, the Snow and Avalanche Research SLF, and the Holfuy station of the Grischa paragliding club. Temperature measurements were taken from the MeteoSwiss station in Klosters (Hervo, 2019) and the snow drift station installed at Gotschnagrat (Walter and Huwald, 2019; Walter et al., 2020). For the analysis of the whole clouds, a vertically pointing cloud radar (Model Mira-36, METEK GmbH, Germany; Görsdorf et al., 2015) was installed in Wolfgang. INPCs were measured in the valley in Wolfgang $(1630 \mathrm{~m})$ and on the mountain top of Weissfluhjoch $(2670 \mathrm{~m})$, where ambient aerosol was sampled through heated inlets using a high-flow-rate impinger (Bertin Technologies, Model Coriolis $\mu$, France). The samples were analyzed for the INPC immediately on-site with a drop-freezing technique using DRINCZ (Drop Freezing Ice Nuclei Counter Zurich; David et al., 2019) of the Swiss Federal Institute of Technology in Zurich (ETH) in Wolfgang 

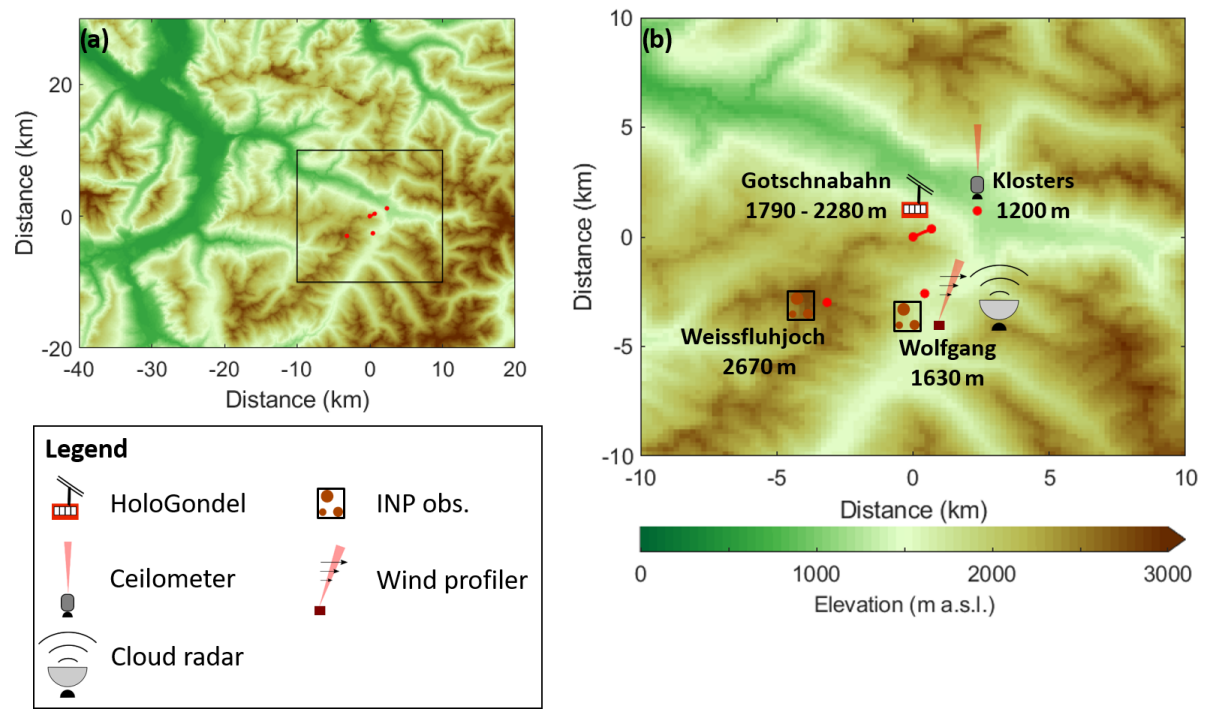

Figure 1. Overview of the measurement location and the experimental setup. The geographical location of the Gotschnabahn and the surrounding topography is shown in (a). An enlarged section of the measurement sites (black rectangle in a) and the instrument setup are shown in (b). The elevation data were taken from the digital height model DHM25 of the Federal Office of Topography swisstopo: https://shop.swisstopo.admin.ch/de/products/height_models/dhm25200 (last access: 9 March 2020).

and the University of Basel's LINDA (LED-based ice nucleation detection apparatus; Stopelli et al., 2014) at Weissfluhjoch as described in Mignani et al. (2021). The detection limit of the INPC (lowest concentration measurable) was calculated according to Vali (1971) considering the concentration obtained if only one (first) drop froze. A detection limit of $5.2 \times 10^{-4}$ and $4.9 \times 10^{-4} \mathrm{~L}^{-1}$ has been determined for Wolfgang and Weissfluhjoch, respectively.

\subsection{HoloGondel}

The HoloGondel platform consists of the HOLographic Imager for Microscopic Objects 3G (HOLIMO 3G in Beck et al., 2017) - which records the concentration, size distribution, and shapes of cloud particles - and a temperature and relative-humidity sensor (HygroMet4, Rotronic) in a ventilated housing (RS24T, Rotronic) as well as a pressure sensor (Fig. 2). During the RACLETS campaign, the platform was installed on one of the gondolas running at the upper section between the Gotschnagrat mountain station $(2280 \mathrm{~m})$ and the middle station at Gotschnaboden $(1790 \mathrm{~m})$, covering a horizontal distance of about $830 \mathrm{~m}$. To avoid any influence by the gondola stations on the measurements, data were only used if the difference between the pressure measured on the gondola and the pressure measured at the stations was more than $1.5 \mathrm{hPa}$, corresponding to a vertical distance of more than $15 \mathrm{~m}$ and a total distance of about $30 \mathrm{~m}$ between the gondola and the stations. The gondola runs with a maximum speed of about $6 \mathrm{~m} \mathrm{~s}^{-1}$, leading to a total measurement time of about $140 \mathrm{~s}$ per ride. To avoid influences from the gondola and its swing arm, only measurements of uphill rides were analyzed, when the setup was in front of the gondola in the direction of travel.

HOLIMO $3 \mathrm{G}$ is an open-path instrument, which uses digital in-line holography. Holograms of the sample volume between the two towers (see Fig. 2b) are recorded, of which $13.7 \mathrm{~cm}^{3}$ was considered for the analysis, producing a $3 \mathrm{D}$ distribution of the cloud particles between the two towers and a 2D image of each cloud particle. A more detailed description of the measurement principle can be found in Beck et al. (2017) and Henneberger et al. (2013). The pixel size is $3.1 \mu \mathrm{m}$, which allows us to observe cloud particles larger than $6.2 \mu \mathrm{m}$ (Beck et al., 2017). The differentiation between ice and liquid is based on the shape of the particles (circular vs. non-circular). This is possible for particles larger than approximately $25 \mu \mathrm{m}$, depending on the shape of the ice particles (Henneberger et al., 2013).

A neural network for particles larger than $25 \mu \mathrm{m}$ (Touloupas et al., 2020) and a decision tree for particles smaller than $25 \mu \mathrm{m}$ in their major axis were used to separate cloud droplets from ice crystals and sort out artifacts, which are falsely identified as cloud particles by the software. All ice crystals were manually confirmed after the automated classification. Therefore, the uncertainty in the concentration of ice particles can be estimated with $\pm 5 \%$ for ice crystals larger than about $100 \mu \mathrm{m}$ and $\pm 15 \%$ for ice crystals smaller than $100 \mu \mathrm{m}$ (Beck, 2017). All ice particles were also manually classified into the habits "plates"; "columns"; "irregular"; "aged ice" (rimed particles and aggregates); and "unidentified", referring to ice crystals, which could not be classified because they were too small or because their orientation did not allow a decision on their habit. 

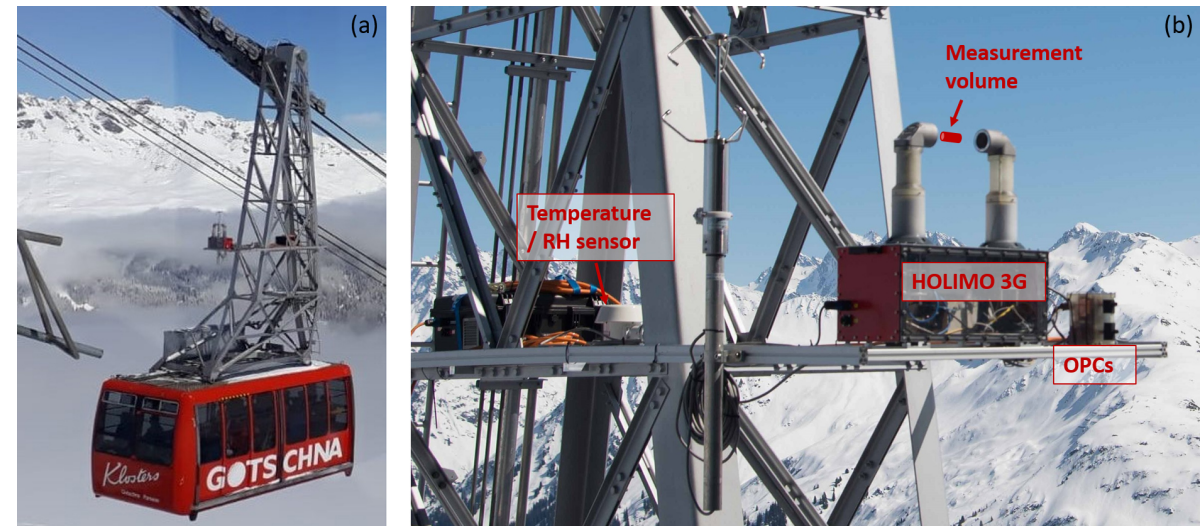

Figure 2. The HoloGondel platform installed on the Gotschnabahn in (a) and an enlarged picture of the platform in (b), showing HOLIMO $3 \mathrm{G}$ with its measurement volume between the two towers, two optical particle counters (not used in this study) next to HOLIMO, and the temperature and relative-humidity $(\mathrm{RH})$ sensor. The sonic anemometer was turned off due to a limited supply of power.

Plates and columns are hexagonal prisms with the diameter of the hexagonal basis $a$ and the prism height $h$. Plates have a dimension of $a>h$, while columns have a dimension of $a \leq h$. For the uncertainty in the different habits, the counting uncertainty $(\sqrt{N} / V ; N$ : number of crystals; $V$ : measurement volume) was added because of their relatively low number compared to the measurement volume. The uncertainty in cloud droplets is estimated to be $\pm 6 \%$ as determined for the classification with the neural network in Touloupas et al. (2020). Again, for droplets larger than $40 \mu \mathrm{m}$ the counting uncertainty was added due to their relatively small numbers.

\section{Case study 22 February 2019}

\subsection{Weather situation}

On 22 February 2019, a ridge was located in front of Switzerland, which guided air masses from the north to the Davos region. A trough over Russia reached relatively far to the south supporting the rise of air masses over Germany, Austria, and eastern Switzerland, which were all covered by stratiform clouds. From the cloud radar measurements (Fig. 3a), it can be anticipated that the cloud top height was about $4 \mathrm{~km}$ in the Davos region, referring to a cloud top temperature of around $-8^{\circ} \mathrm{C}$ as measured by a radiosonde launched at 10:25 UTC from Wolfgang. Between 05:00 and 09:00 UTC, the cloud radar showed a midlevel cloud above the stratiform cloud, reaching from about 4.5 to about $6.5 \mathrm{~km}$, that might have acted as a seeder cloud in the early morning.

As can be inferred from the ceilometer data, light precipitation started at around 07:00 UTC in Klosters, where the valley station of the Gotschnabahn is located (Fig. 3b). The cloud base was located slightly above the height of the Gotschnaboden during the precipitation period, which lasted until about 10:30 UTC, when the cloud began to dissipate. Measurements with HoloGondel were taken between
08:00 and 10:00 UTC. The rides used for the analysis are shown as gray lines in Fig. 3. The temperatures and relative humidities at Gotschnaboden and Gotschnagrat (Fig. 3c and d) are derived from measurements of the highest and lowest point of the measurements on the gondola and are therefore only available when the gondola was in operation and close to one of the stations. During the measurement period, the temperature in Klosters increased from about +1.5 to $+3.5^{\circ} \mathrm{C}$ at a relative humidity of about $80 \%$, while the measurements on the gondola were taken mainly between 0 and $-2.5{ }^{\circ} \mathrm{C}$ at relative humidities above $95 \%$. The melting layer can be inferred from the dark band of the ceilometer data (Sassen et al., 2005) below Gotschnaboden (Fig. 3b), which was measured above Klosters and may slightly differ at Gotschnaboden.

The main wind direction was from north to northeast as can be inferred from the wind profiler measurements taken in Wolfgang in Fig. 4b. However, the ground measurements show that the wind direction was strongly influenced by the orography (Fig. 4a). The valley north of the Gotschnabahn forced the wind direction to the northwest as can be seen from the wind measurements on Gotschnagrat. Thus, air masses measured on Gotschnabahn were pushed up the valley coming from northwest and must have been lifted through the melting layer before reaching the measurement site.

The slope inclination in the wind direction measured at Gotschnagrat is about $7^{\circ}$ (averaged over Gotschnagrat and $1 \mathrm{~km}$ northwest). Assuming that the measured horizontal wind of about $5 \mathrm{~m} \mathrm{~s}^{-1}$ (Fig. 4) was blown up the slope without friction, the vertical wind speed reached about $0.6 \mathrm{~m} \mathrm{~s}^{-1}$. The eddy dissipation rate, which is a measure for turbulence, was calculated from the wind profiler and cloud radar measurements as described in Griesche et al. (2020) and reached values between 20 and $90 \mathrm{~cm}^{2} \mathrm{~s}^{-3}$ at an altitude of 1800 to $2300 \mathrm{~m}$ between 08:00 and 10:00 UTC over Wolfgang. Such values were reported in stratiform clouds (Borque 

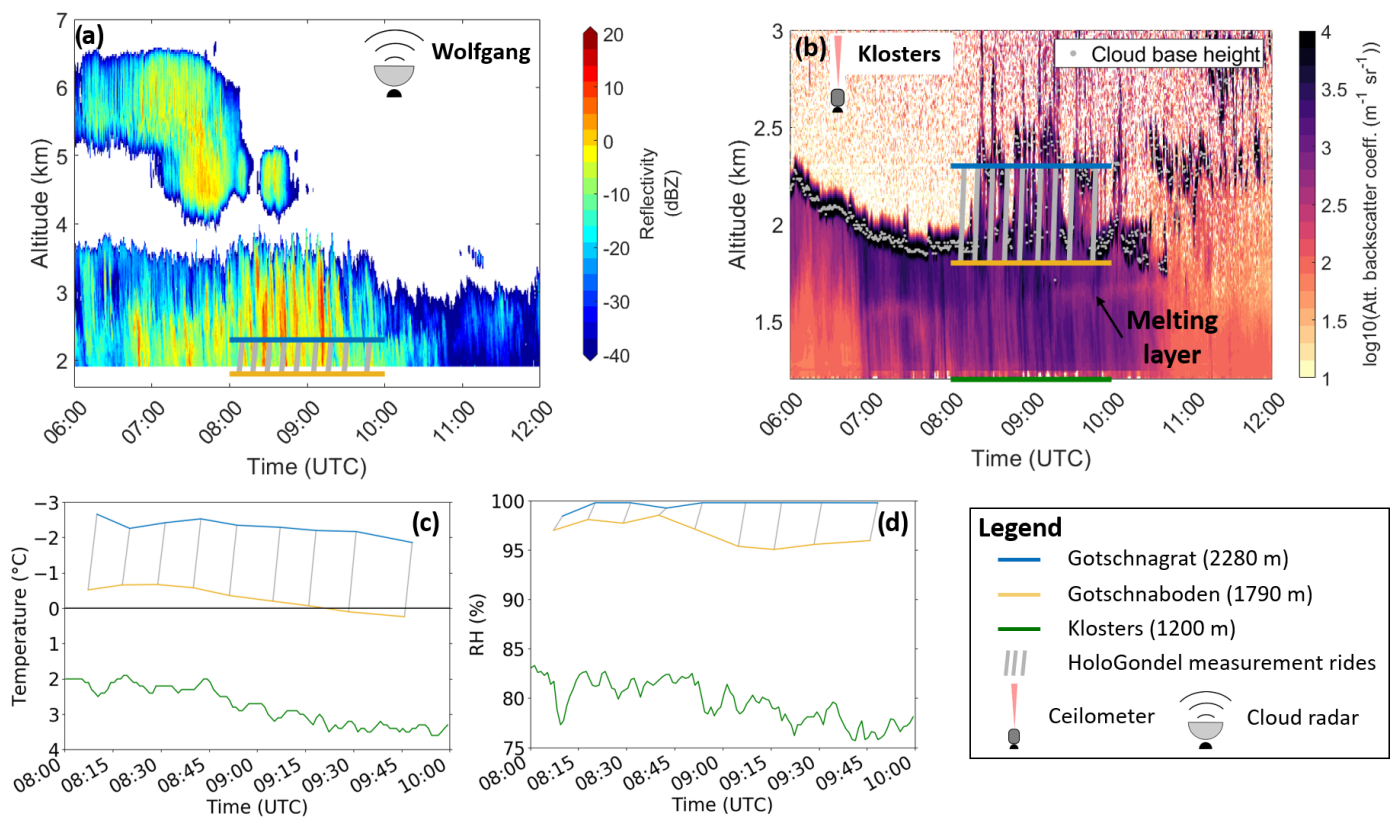

Figure 3. Observations of the reflectivity measured by the cloud radar installed in Wolfgang are shown in (a). The ceilometer data in (b) show the estimated cloud base with gray dots above Klosters. A dark band underneath the cloud base indicates the melting layer. Temperature and relative-humidity measurements at the highest (closest to Gotschnagrat) and lowest point (closest to Gotschnaboden) of the gondola measurements and Klosters during the time HoloGondel was measuring are shown in (c) and (d), respectively.
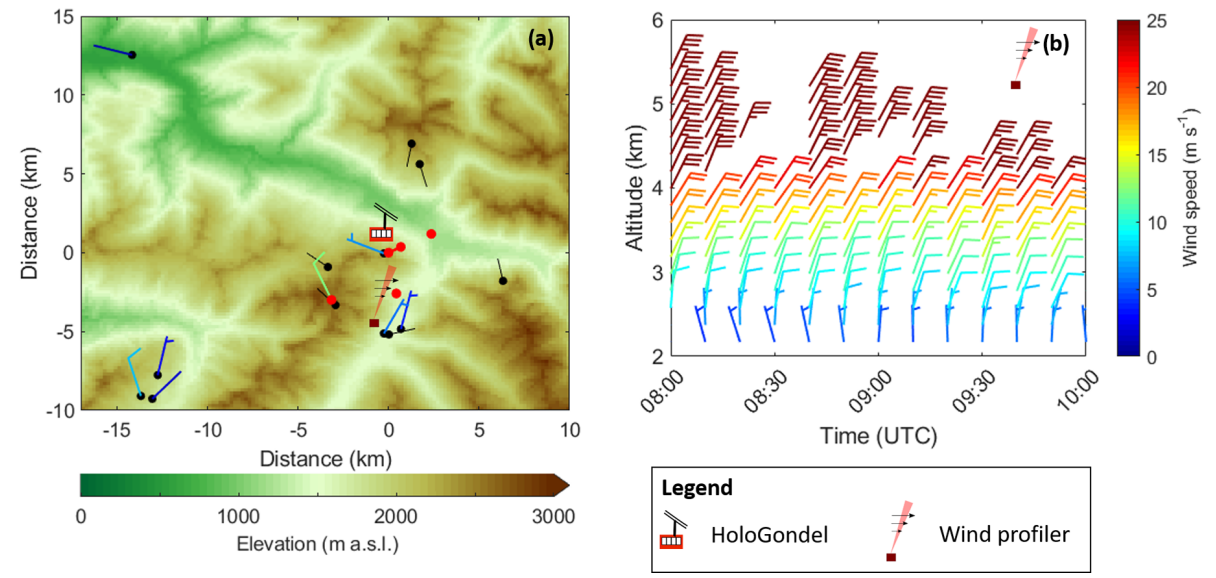

Figure 4. The wind direction and speed at different weather stations averaged between 08:00 and 10:00 UTC in the Davos region are shown in (a). The colors of the wind barbs show the wind speed according to the color bar, while stations with black lines only report wind direction. The wind profiler data, measured in Wolfgang, are shown in (b). The elevation data were taken from the digital height model DHM25 of the Federal Office of Topography swisstopo: https://shop.swisstopo.admin.ch/de/products/height_models/dhm25200 (last access: 9 March 2020).

et al., 2016) as well as in cumulus clouds with weak updrafts (Siebert et al., 2006). Since no measurements of turbulence are available over Klosters, we assume that similar turbulence is present at the measurement site.

\subsection{In situ measurements}

Between 08:00 and 10:00 UTC, a total volume of 43.7 L was measured by HOLIMO, distributed over nine uphill rides, each contributing between 2.6 and $8.2 \mathrm{~L}$. The difference in the measurement volumes is due to different onsets and offsets of the automated recording. HOLIMO observed aged ice crystals (here defined as aggregates and rimed particles), irregular particles, plates, and very few small columns (see Fig. 5). About $35 \%$ of all ice crystals were classified as unidentified because they were too small, or the particle orientation made a decision on its habit inconclusive. As dis- 


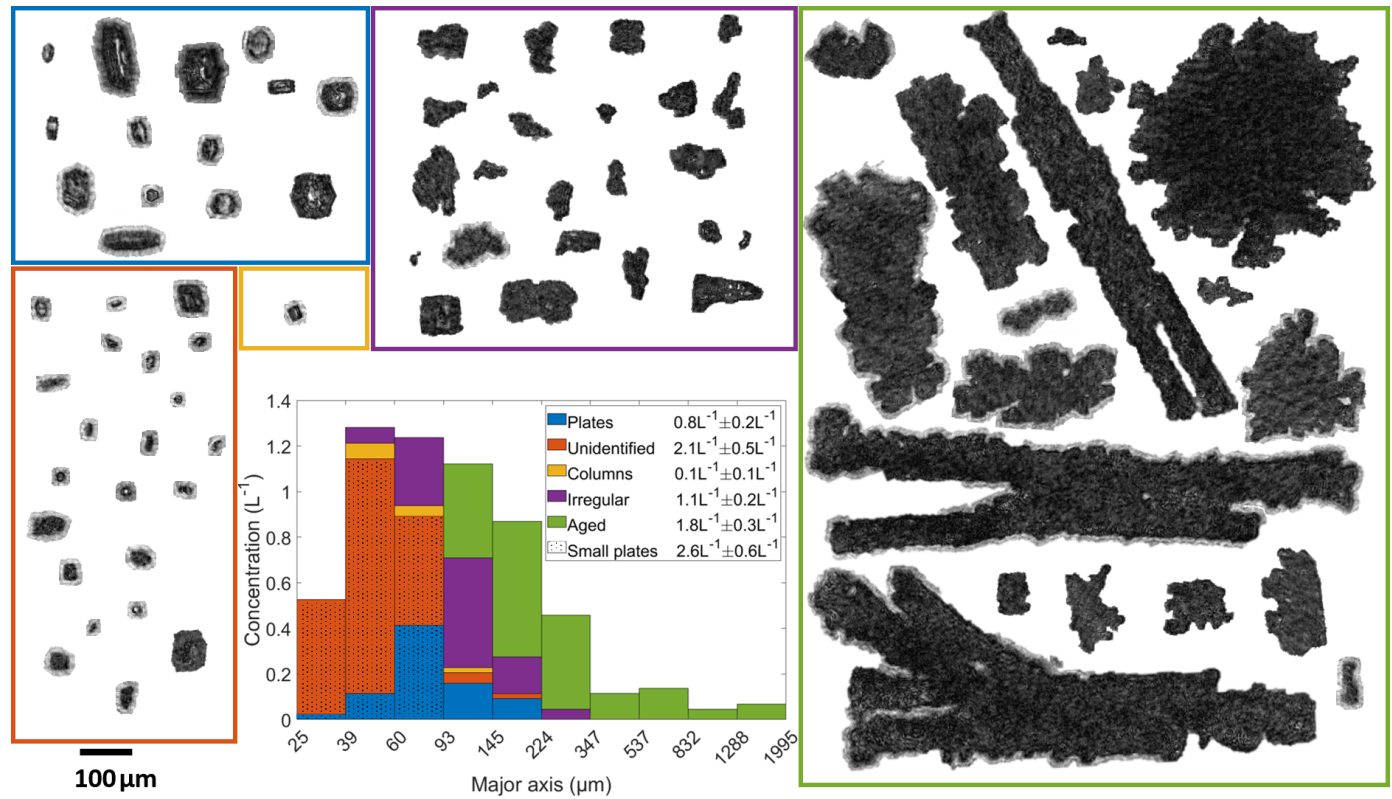

Figure 5. The figure shows a randomly selected sample of ice crystals, which were observed in the cloud together with a stacked size distribution of the different habits. The total concentrations together with the uncertainties in each habit are shown in the legend of the histogram. Unidentified crystals as well as plates smaller than $93 \mu \mathrm{m}$ in their major axis are referred to as "small plates" as discussed (see text for more details).

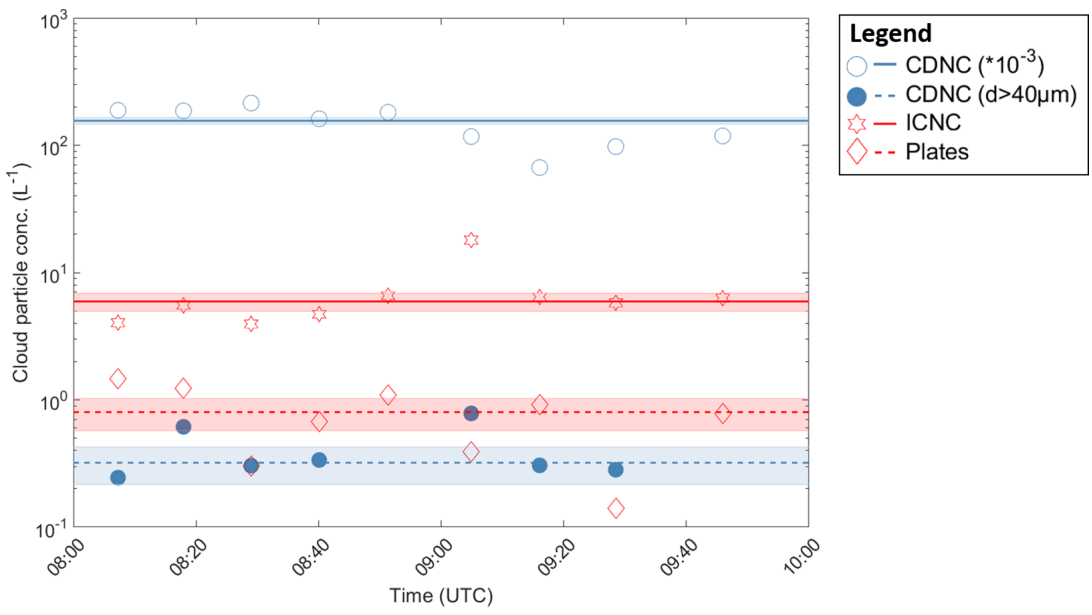

Figure 6. The ICNC, CDNC, CDNC for droplets larger than $40 \mu \mathrm{m}$, and the concentration of plates averaged over each of the nine measurement rides are shown with the four different symbols. The corresponding lines show the mean concentration of the complete measurement volume with the shaded areas as the uncertainty in the mean concentrations.

cussed in Sect. 4.1, unidentified particles as well as plates smaller than $93 \mu \mathrm{m}$ are referred to as small plates. They are marked with dots in the histogram plot of the ice crystal size distribution in Fig. 5.

The concentrations of ice crystals and cloud droplets stayed relatively constant over the measurement period (see Fig. 6). Taking the whole measurement period into account, a mean cloud droplet number concentration (CDNC) of $156 \mathrm{~cm}^{-3} \pm 9 \mathrm{~cm}^{-3}$ and a mean ICNC of $6 \mathrm{~L}^{-1} \pm 1 \mathrm{~L}^{-1}$ were measured. Between the different rides the $\mathrm{CDNC}$ varied between 67 and $215 \mathrm{~cm}^{-3}$ and the ICNC between 4 and $18 \mathrm{~L}^{-1}$. The most commonly observed pristine ice particle habit was plates, with a mean concentration of $0.8 \mathrm{~L}^{-1} \pm 0.2 \mathrm{~L}^{-1}$, varying between 0.1 and $1.5 \mathrm{~L}^{-1}$ between the different rides. Note that this is a lower estimate since the software has difficulties in detecting transparent particles, and depending on the size and orientation, plates may be hard to identify. Besides the ice particle habits, a mean concentration of droplets larger than $40 \mu \mathrm{m}$ in diameter of $0.3 \mathrm{~L}^{-1} \pm 0.1 \mathrm{~L}^{-1}$, varying between 0 and $0.8 \mathrm{~L}^{-1}$ between 
the different rides, was observed. It should be mentioned that the missing observations of plates or large droplets during single rides could be a stochastic effect due to the relatively low concentrations compared to the measurement volumes of each ride; i.e., for the smallest measurement volume of $2.6 \mathrm{~L}^{-1}$, one observed particle results in a particle concentration of $0.4 \mathrm{~L}^{-1}$. In the following, we consider the whole measurement period and site as one measurement volume, where the cloud particle concentrations are constant.

The INPC was measured in the valley in Wolfgang $(1630 \mathrm{~m})$ and on the mountain top of Weissfluhjoch $(2670 \mathrm{~m})$ (see Fig. 1 for the geographical positions) simultaneously at 08:00 and 10:00 UTC on 22 February 2019. No INP was detected for temperatures higher than $-6^{\circ} \mathrm{C}$ at both sites. Therefore, the upper estimate of the INPC at the measurement site $\left(T>-3^{\circ} \mathrm{C}\right)$ is equal to the detection limit and on the order of $5 \times 10^{-4} \mathrm{~L}^{-1}$ for both sites, which lies several orders below the measured ICNC.

\section{Discussion}

\subsection{Estimation of the secondary-ice crystal number concentration}

Since the INPC at the measurement location lies several orders of magnitude below the ICNC, the contribution from primary-ice nucleation will be neglected. Therefore, the concentration of secondary-ice crystals can be estimated from the concentration of ice crystals that have newly formed and grown at the same location. The measurements were taken at temperatures warmer than $-3{ }^{\circ} \mathrm{C}$. In this temperature regime, newly formed ice crystals grow into plates (Libbrecht, 2005; Bailey and Hallett, 2009). Figure 5 shows the shapes and the size distribution of the ice crystals divided logarithmically into nine size bins. The histogram plot shows that the majority of the classified particles smaller than $93 \mu \mathrm{m}$ were plates (54\% if unidentified particles are excluded; Fig. 5), while aged crystals can only be found above that size. Hence, we take $93 \mu \mathrm{m}$ as a threshold to divide between newly formed ice crystals and those which sedimented from above.

About $70 \%$ of the ice crystals smaller than $93 \mu \mathrm{m}$ (from now on referred to as "small ice") could not be classified into a certain habit because the resolution was too low. Yet, a transparent part observed in the middle of many of these particles (see Fig. 5) supports the assumption based on the temperature regime that these ice crystals are actual plates. In the following, small ice classified as plates including the unidentified particles is referred to as "small plates".

A plate with a maximum dimension of $93 \mu \mathrm{m}$ has a fall velocity of about $0.05 \mathrm{~m} \mathrm{~s}^{-1}$ (using the equations given in Pruppacher and Klett, 2010), which is 1 order of magnitude lower than the estimated updraft of about $0.6 \mathrm{~m} \mathrm{~s}^{-1}$. This supports the assumption that small plates are unlikely to have sedimented from above. About $4 \%$ of the small ice was classified as columns. The few observed columns have an aspect ratio close to 1 (see Fig. 5), which is typical for columns growing at temperatures just below $-3^{\circ} \mathrm{C}$ at low supersaturation (Libbrecht, 2005; Bailey and Hallett, 2009), and therefore they must have sedimented from slightly higher altitudes. This is possible because columns have a higher fall velocity than plates (a column with a length of $93 \mu \mathrm{m}$ falls with about $0.3 \mathrm{~m} \mathrm{~s}^{-1}$ using the equations given in Pruppacher and Klett, 2010). About $10 \%$ of the small ice was classified as irregular particles. These could be large secondary-ice splinters. However, the fall velocity of irregular particles is hard to assess, and it remains unclear if they have fallen from above or formed at the measurement site by SIP. Based on these assumptions, the lower estimate of the secondary-ice concentration, which has formed and grown at the measurement site, is equal to the concentration of small plates as defined above and is on the order of $2.6 \mathrm{~L}^{-1} \pm 0.6 \mathrm{~L}^{-1}$.

The time a plate needs to grow to $93 \mu \mathrm{m}$ is hard to assess at temperatures close to $0{ }^{\circ} \mathrm{C}$ because small variations in the environmental conditions, e.g., a temperature fluctuation of only $0.5^{\circ} \mathrm{C}$, can change the growth time on the order of several minutes. To calculate the growth time, we use the general equation of the ice particle growth by vapor diffusion given in Fukuta and Takahashi (1999). Using the mass-size relation of hexagonal plates from Mitchell et al. (1990) and assuming water vapor saturation over liquid at a temperature of $-2^{\circ} \mathrm{C}$, a splinter of $5 \mu \mathrm{m}$ needs about $9 \mathrm{~min}$ to grow to a size of $93 \mu \mathrm{m}$ and about $5 \mathrm{~min}$ to grow to a size of $60 \mu \mathrm{m}$. Thus, for any given time, a plate of $93 \mu \mathrm{m}$ is 4 min older than a plate of $60 \mu \mathrm{m}$ if the temperature is constant at $-2{ }^{\circ} \mathrm{C}$, and the water vapor is saturated over water. Therefore, plates with sizes between 60 and $93 \mu \mathrm{m}$ must have newly formed by SIP within a time span of $4 \mathrm{~min}$. The same calculation can be done for a bigger size interval, e.g., plates between 39 and $93 \mu \mathrm{m}$, which must have newly formed by SIP during a time span of about $6 \mathrm{~min}$. Taking temperature variations in the measurement volume into account, i.e., varying the temperature between -2 and $-1{ }^{\circ} \mathrm{C}$, plates between 60 and $93 \mu \mathrm{m}$ were newly formed by SIP during a time span of 4 to $6 \mathrm{~min}$, while plates between 39 and $93 \mu \mathrm{m}$ were newly formed by SIP during a time span of 6 to 10 min depending on the temperature. The observed concentration of small plates with sizes between 60 and $93 \mu \mathrm{m}$ was $0.9 \mathrm{~L}^{-1} \pm 0.3 \mathrm{~L}^{-1}$, whereas between 39 and $93 \mu \mathrm{m}$ the concentration of small plates was $2.1 \mathrm{~L}^{-1} \pm 0.5 \mathrm{~L}^{-1}$ averaged over the $2 \mathrm{~h}$ measurement period. Thus, $0.9 \mathrm{~L}^{-1} \pm 0.3 \mathrm{~L}^{-1}$ of secondary ice has formed within 4 to 6 min and $2.1 \mathrm{~L}^{-1} \pm 0.5 \mathrm{~L}^{-1}$ within 6 to $10 \mathrm{~min}$. Taking all named uncertainties into account, the rate of secondary-ice production during our case study was $0.24 \mathrm{~L}^{-1} \mathrm{~min}^{-1} \pm 0.09 \mathrm{~L}^{-1} \mathrm{~min}^{-1}$.

\subsection{Contribution of different SIP mechanisms}

Droplets larger than $40 \mu \mathrm{m}$ up to a size of $380 \mu \mathrm{m}$ in diameter were observed between 0 and $-2.7^{\circ} \mathrm{C}$. Korolev et al. 
(2020) explained the occurrence of large droplets just above the melting layer with a recirculation process (see Sect. 1.2). Ice particles fall through the melting layer and melt into drizzle drops, which can be reintroduced into the cloud by sufficiently high updrafts. The estimated updraft in this case study is about $0.6 \mathrm{~m} \mathrm{~s}^{-1}$, which is equal to the fall speed of a $150 \mu \mathrm{m}$ droplet (Rogers and Yau, 1989). Most of the observed droplets were smaller than $150 \mu \mathrm{m}$ and could be lifted up in the clouds by the updraft, while the remaining ones could have been brought into the cloud by local turbulences. Also note that the updraft velocity is a very rough estimate; increasing it by $0.2 \mathrm{~m} \mathrm{~s}^{-1}$ is already enough to lift $86 \%$ instead of $79 \%$ of the observed droplets.

Droplet fragmentation requires the presence of large droplets ( $>\approx 40 \mu \mathrm{m}$; e.g., Lawson et al., 2015; Korolev et al., 2020) and has no temperature constraint towards high temperatures. It is therefore a possible mechanism to explain the observed secondary ice. Collisional breakup cannot be completely ruled out, but it is not expected to produce high secondary ICNCs at warm temperatures as outlined in the introduction. Furthermore, the missing observation of fragmentlike ice particles (e.g., broken-off branches) is evidence that collisional breakup was not very active. Moreover, fragments from collisional breakup are not necessarily small particles and therefore could be miscounted as aged or irregular ice in this study.

The rime-splintering process and ice fragmentation during thermal shock can both be excluded from being active because they require lower temperatures. Additionally, INP activation in transient supersaturation around freezing drops is unlikely to be active in a relatively warm environment (Korolev et al., 2020). As MPCs are supersaturated with respect to ice, the requirements for ice fragmentation during sublimation are also not fulfilled (Korolev et al., 2020).

Ice crystals can partially melt and create fragments, which can be lifted back into the cloud. However, the ice crystals have to be sufficiently small to be lifted, while at the same time, small ice crystals are likely to completely melt before re-entering the cloud. Furthermore, the breakup rates of this process depend on temperature and humidity and largely on the initial shape of the ice crystals (Korolev and Leisner, 2020). Oraltay and Hallett (1989) observed no sublimation breakup for columnar and plate-like crystals and breakup during melting only at relative humidities below $90 \%$. The shapes of ice crystals in our study are mostly solid particles that have columnar and plate-like shapes (Fig. 5), and the relative humidity on the gondola never dropped below $95 \%$ (Fig. 3d). Taking all these considerations into account, we assume that ice fragmentation during melting has a negligible effect on the SIP.

Therefore, we expect that most of the small plates emerged from droplet fragmentation and that the orographically induced updrafts serve as a constant supply of new droplets larger than $40 \mu \mathrm{m}$ in diameter, which originate from melted ice crystals. A schematic of this recirculation process in

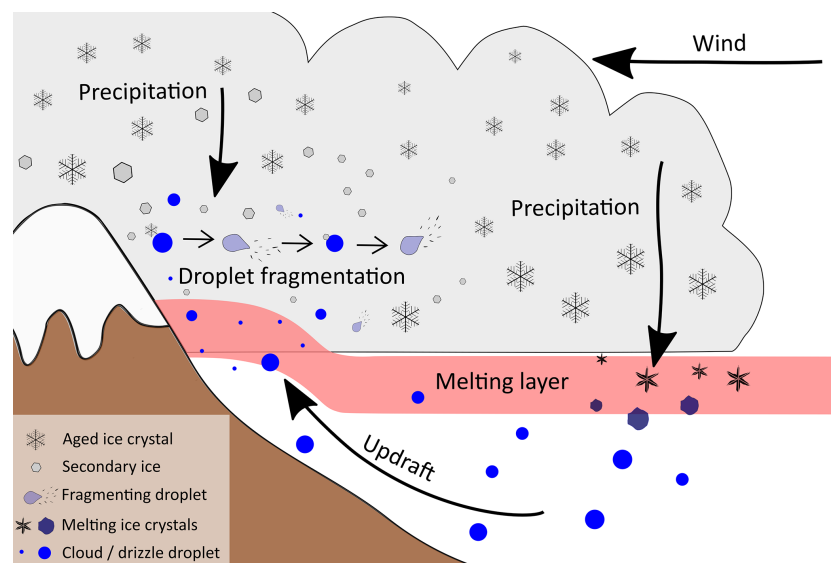

Figure 7. Schematic of the recirculation process, which was introduced by Korolev et al. (2020) and adapted for an updraft created by a mountain slope. Aged ice crystals sediment from the cloud and turn into drizzle-sized drops when they fall through the melting layer. These drops are reintroduced into the cloud by wind forced up the mountain slope (updraft), where they freeze when they collide with aged ice crystals and fragment upon freezing. The small fragments grow into plates due to the environmental conditions $\left(T>-3^{\circ} \mathrm{C}\right)$ and may hit other droplets, which again freeze and possibly fragment.

mountainous regions is shown in Fig. 7. Because new droplets are continuously provided, we can assume that our measurements reflect a steady state such that we observe freshly produced as well as aged particles simultaneously. The combination of SIP above the melting layer and high updrafts on the windward slope will transport the secondaryice crystals to higher altitudes, where they influence the cloud microphysics.

\subsection{Parametrization of SIP by droplet fragmentation at warm temperatures}

Here we derive a parametrization of the SIP by droplet fragmentation at temperatures close to $0^{\circ} \mathrm{C}$, when primaryice nucleation can be neglected and droplets freeze only by the collision with ice crystals, which either sedimented from above or formed by SIP. Like Korolev et al. (2020), we assume that only droplets larger than $40 \mu \mathrm{m}$ are likely to contribute to SIP by droplet fragmentation. To calculate the splinter generation rate of a droplet with diameter $d_{n}\left(g_{\mathrm{sp}}\left(d_{n}\right)\right)$, the droplet freezing rate by collision $\left(f_{\text {col }}\left(d_{n}\right)\right)$ has to be multiplied by the droplet fragmentation probability during freezing $\left(p_{\mathrm{df}}\left(d_{n}\right)\right)$ and the number of splinters per fragmenting droplet $\left(N_{\mathrm{sp}}\left(d_{n}\right)\right)$ :

$g_{\text {sp }}\left(d_{n}\right)=f_{\text {col }}\left(d_{n}\right) \cdot p_{\text {df }}\left(d_{n}\right) \cdot N_{\text {sp }}\left(d_{n}\right)$.

To obtain the total splinter generation rate $\left(G_{\mathrm{sp}}\right)$ in a volume $V$, which contains $N_{\mathrm{d}>40 \mu \mathrm{m}}$ droplets with diameters larger than $40 \mu \mathrm{m}$, the sum of $g_{\mathrm{sp}}\left(d_{n}\right)$ over all droplets with diameter $d_{n}\left(n=1,2, \ldots, N_{\mathrm{d}>40 \mu \mathrm{m}}\right)$ has to be divided by $V$ : 
$G_{\text {sp }}=\frac{1}{V} \sum_{n=1}^{N_{\mathrm{d}>40 \mu \mathrm{m}}} g_{\mathrm{sp}}\left(d_{n}\right)$.

The probability that a droplet with a fall velocity of $v\left(d_{n}\right)$ collides with an ice crystal with an equivalent particle area diameter $a_{j}$ and freezes is equal to the collision efficiency $E\left(d_{n}, a_{j}\right)$. It needs to be multiplied by the combined cross-section of the ice crystal and the droplet $\left(0.25 \cdot \pi \cdot\left(d_{n}+\right.\right.$ $\left.a_{j}\right)^{2}$ ) and the absolute relative velocity between those two $\left(\left|v(a j)-v\left(d_{n}\right)\right|\right)$ to obtain the collection kernel. To calculate the freezing rate of a droplet in volume $V$, the sum of the collection kernel between the droplet and each ice crystal in the same volume with an equivalent particle area diameter $a_{j}$ ( $j=1,2, \ldots, N_{\text {ice }} ; N_{\text {ice }}$ : number of ice crystals) has to be divided by $V$ :

$$
\begin{aligned}
f_{\mathrm{col}}\left(d_{n}\right) & \approx \frac{1}{V} \sum_{j=1}^{N_{\mathrm{ice}}} E\left(d_{n}, a_{j}\right) \cdot\left|v\left(a_{j}\right)-v\left(d_{n}\right)\right| \\
& \cdot \frac{\pi \cdot\left(d_{n}+a_{j}\right)^{2}}{4} .
\end{aligned}
$$

The probability of droplet fragmentation is size-dependent (Takahashi and Yamashita, 1969; Kolomeychuk et al., 1975; Lauber et al., 2018). For a fragmentation to occur, the surface energy has to be overcome, which is proportional to $d_{n}^{2}$. Therefore, we expect $p_{\mathrm{df}}\left(d_{n}\right)=c \cdot d_{n}^{2}$ for some constant $c$. The constant $c$ can be estimated by assuming a fragmentation probability of $40 \%$ for droplets with $d_{n}=300 \mu \mathrm{m}$ at temperatures higher than $-2.5^{\circ} \mathrm{C}$, i.e., $p_{\mathrm{df}}\left(d_{n}=300 \mu \mathrm{m}\right)=0.4$, as measured by Keinert et al. (2020). This yields a droplet fragmentation probability per freezing droplet of

$p_{\mathrm{df}}\left(d_{n}\right) \approx 4.4 \times 10^{6} \mathrm{~m}^{-2} \cdot d_{n}^{2}$,

which differs from other studies, where the probability of droplet fragmentation follows a normal distribution centered at $-15^{\circ} \mathrm{C}$ independent of droplet size, with a probability close to $0 \%$ for slightly sub-zero temperatures (e.g., Sullivan et al., 2018b, a; Sotiropoulou et al., 2020b). However, the study of Keinert et al. (2020) showed that droplet fragmentation is also likely to happen at temperatures close to $0{ }^{\circ} \mathrm{C}$.

The concentration of splinters produced per fragmentation event could not be quantified until now because many of the splinters being produced during a fragmentation event might be too small to be observed with the available measurement techniques (Lauber et al., 2018; Keinert et al., 2020). Here we consider the maximum number of splinters observed during a breakup event for different droplet sizes, which were summarized by Lauber et al. (2018) from different studies, to be the best estimate available. The data points suggest a linear correlation between the number of splinters being produced per droplet $N_{\mathrm{sp}}\left(d_{n}\right)$ and the droplet diameter $d_{n}$. Applying a linear regression, $N_{\mathrm{sp}}$ can be estimated as
$N_{\mathrm{sp}}\left(d_{n}\right) \approx 9 \times 10^{4} \mathrm{~m}^{-1} \cdot d_{n}$.

The splinter generation rate in volume $V$ at temperatures close to $0^{\circ} \mathrm{C}$ in MPCs is subsequently given by

$$
\begin{aligned}
G_{\mathrm{sp}} & \approx 9.9 \times 10^{10} \cdot \pi \mathrm{m}^{-3} \cdot \frac{1}{V^{2}} \sum_{n=1}^{N_{\mathrm{d}>40 \mu \mathrm{m}}} d_{n}^{3} \sum_{j=1}^{N_{\text {ice }}} E\left(d_{n}, a_{j}\right) \\
\cdot & \left|v\left(a_{j}\right)-v\left(d_{n}\right)\right| \cdot\left(d_{n}+a_{j}\right)^{2} .
\end{aligned}
$$

\subsubsection{Application of the parametrization to the case study}

In this section, the parametrization derived for SIP by droplet fragmentation for temperatures close to $0^{\circ} \mathrm{C}$ in the absence of INPs is applied to the presented case study. For simplicity, we assume that the ICNC as well as the size and shape distribution of the ice crystals stays constant over the whole measurement period of $2 \mathrm{~h}$, meaning that any ice crystal which leaves the measurement volume is immediately replaced by a new one of the same size and shape. The same is valid for cloud droplets, which leave the measurement volume or freeze and potentially produce secondary-ice splinters. Thus, we assume a constant production of secondary ice. Furthermore, we expect that droplets larger than $40 \mu \mathrm{m}$ have a collision efficiency of $E\left(d_{n}, a_{j}\right)=1$ with any ice crystal.

To calculate the fall velocities of the ice crystals, we divide them into plates and lump graupel. The former includes the classes "plates" and "unidentified", while the later includes all other ice crystals (see Sect. 2.2 for a more detailed description of the classes). The fall velocity of plates was calculated with the following equation from Pruppacher and Klett (2010) (converted to SI base units) using the maximum dimension of plates $L_{\mathrm{pla}}$ :

$v\left(L_{\mathrm{pla}}\right) \approx 156 \mathrm{~m}^{0.14} \mathrm{~s}^{-1} \cdot L_{\mathrm{pla}}^{0.86}$.

To derive the fall speed of lump graupel with a maximum dimension of $L_{\text {gra }}$, we use the equation provided by Locatelli and Hobbs (1974) (again, converted to SI base units):

$v\left(L_{\text {gra }}\right) \approx 124 \mathrm{~m}^{0.34} \mathrm{~s}^{-1} \cdot L_{\text {gra }}^{0.66}$.

This yields a splinter generation rate of $0.06 \mathrm{~L}^{-1} \mathrm{~min}^{-1} \pm 0.02 \mathrm{~L}^{-1} \mathrm{~min}^{-1}$ of secondary ice, which is about 1 order of magnitude below the estimated production rate of secondary ice of $0.24 \mathrm{~L}^{-1} \mathrm{~min}^{-1} \pm 0.09 \mathrm{~L}^{-1} \mathrm{~min}^{-1}$ derived from the observations.

The most uncertain parameter in Eq. (6) is the number of splinters produced during a droplet fragmentation event. Taking the uncertainties into account and assuming that the proportionality of the number of splinters and the droplet diameter is correct, $N_{\mathrm{sp}}$ has to be on the order of $N_{\mathrm{sp}}\left(d_{n}\right)=$ $\left(4.9 \times 10^{5} \pm 3.1 \times 10^{5}\right) \mathrm{m}^{-1} \cdot d_{n}$ to produce the measured concentrations of small secondary-ice particles. This is equivalent to $99 \pm 62$ splinters produced by a fragmenting droplet 

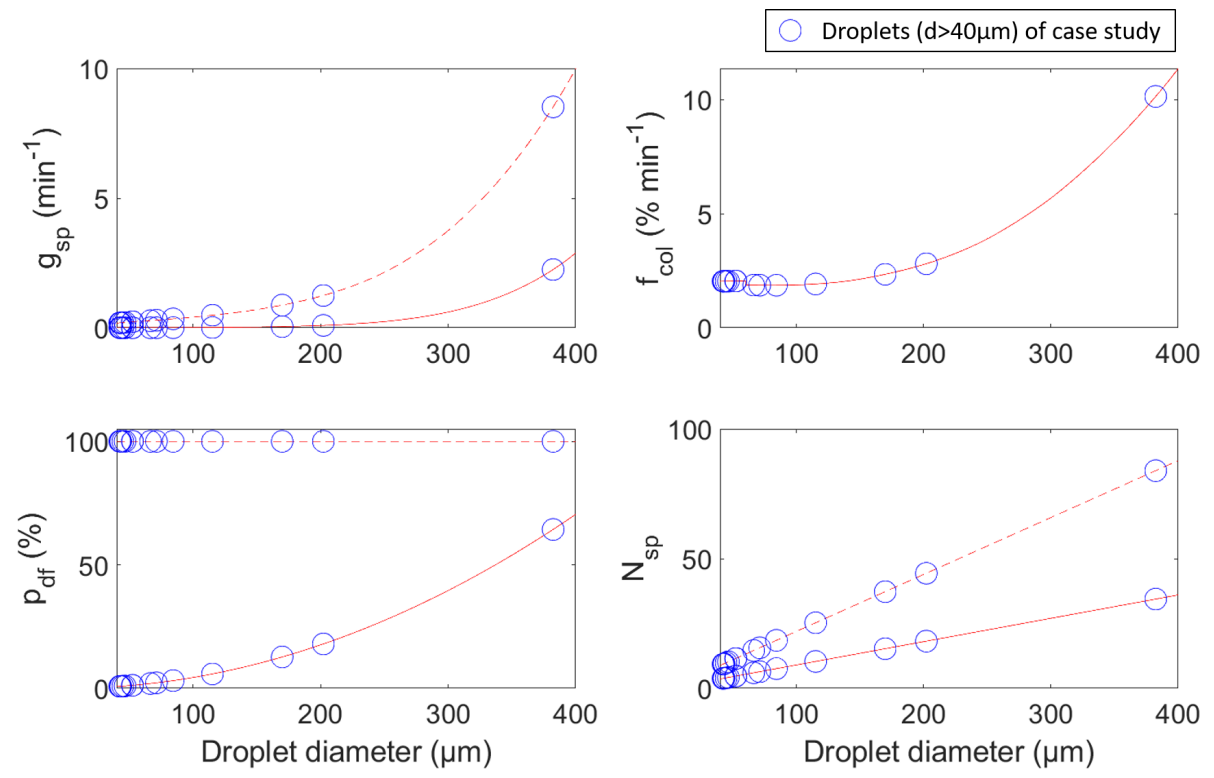

Figure 8. The plots show the different parameters of the splinter generation rate $g_{\mathrm{sp}}\left(d_{n}\right)$ (Eq. 1) for the first assumptions (Eqs. 3-5; solid lines) and for the tuned version of $N_{\mathrm{sp}}$ in turbulent conditions that can explain the observations (Eqs. 9 and 10; dashed lines).

of $200 \mu \mathrm{m}$ in diameter and is 2 to 9 times higher than the first assumption of $N_{\text {sp }}$.

Apart from the average number of splinters produced, also the probability that a droplet fragments when it freezes might be different in the atmosphere from what has been measured in the laboratory. Keinert et al. (2020) showed that droplet fragmentation is significantly higher in moving air than in stagnant air. Therefore, it may be reasonable to assume that $p_{\text {df }}$ is even higher in turbulent conditions, and we expect here that every droplet fragments when it freezes:

$p_{\mathrm{df}}\left(d_{n}\right)=1$.

To explain the observed splinter generation rate of the measurements when turbulent conditions are expected, $N_{\text {sp }}$ needs to be on the order of

$N_{\mathrm{sp}}\left(d_{n}\right)=\left(2.2 \times 10^{5} \pm 1.3 \times 10^{5}\right) \mathrm{m}^{-1} \cdot d_{n}$.

This is equivalent to $44 \pm 26$ splinters produced per fragmenting droplet of $200 \mu \mathrm{m}$ in diameter and is only 1 to 4 times higher than the first assumption of $N_{\mathrm{sp}}$.

The calculated values for each parameter of Eq. (1) are shown in Fig. 8 as a function of droplet size and for each measured droplet individually for the first assumptions (Eqs. 3-5) as well as for the tuned version of $N_{\text {sp }}$ in turbulent conditions that can explain the observations (Eqs. 9 and 10).

\subsubsection{Caveats of the parametrization and its application to the case study}

The first main caveat is that the parametrization was derived solely from laboratory measurements. However, the direct observation of SIP by droplet fragmentation is basically impossible as the process happens on a millisecond timescale (Lauber et al., 2018), and the secondary-ice splinters can be smaller than $10 \mu \mathrm{m}$ (Korolev et al., 2020). Therefore, the laboratory measurements are the best estimate available.

The second main caveat is the parametrization of $N_{\mathrm{sp}}$. The proportionality of $N_{\mathrm{sp}}$ to $d$ was based on only four data points, which were derived from three different studies using different measurement techniques and only show the maximum number of observed fragments as discussed in Lauber et al. (2018). Apart from this, there is no physical basis for this correlation. There are so far no reliable measurements of the average number of fragments being produced per fragmentation, and recent work by Kleinheins et al. (2020) provides an indication that a majority of possible fragment ejections during freezing could not be observed by the applied measurement techniques. The application to the case study suggests that the number of splinters may be up to 9 times higher than assumed in Eq. (5) but critically depends on the largest observed droplet. Until further measurements can constrain the concentration of fragments produced per fragmentation, $N_{\mathrm{sp}}$ remains highly uncertain.

Thirdly, the contribution of the different droplets is highly unbalanced, which can be seen in Fig. 8. For example, the largest droplet $(\sim 380 \mu \mathrm{m})$ in the present case study contributes $97 \%$ to the total amount of the produced concentration of secondary ice when using the first assumptions of $p_{\text {df }}$ (Eq. 4) and $N_{\text {sp }}$ (Eq. 5) and $77 \%$ when expecting turbulent conditions (Eq. 9) with a tuned version of $N_{\mathrm{sp}}$ that can explain the observations (Eq. 10). This imbalance might be a real possibility, and very few large droplets may be enough 
to explain high concentrations of secondary ice, while the contribution of droplets smaller than about $100 \mu \mathrm{m}$ may be negligible. However, the observation of a single droplet with a certain size is statistically insignificant, and more observations are needed to determine the real size distribution of the cloud droplets.

As a fourth caveat, we assume a continuous flow over $2 \mathrm{~h}$ without any vertical gradient for the application to the case study. Since the secondary-ice splinters are expected to be very small, they will be lifted up with the updraft faster than the drizzle drops while they are growing to an observable size. The moment they leave the measurement volume, before they reach a size of $93 \mu \mathrm{m}$, they will not be counted as secondary-ice splinters anymore even though they were produced inside the measurement volume. Therefore, we expect that the secondary-ice concentration is slightly underestimated. Drizzle drops can also produce secondary ice when they are outside the measurement volume, but the secondaryice particles can be lifted into the measurement volume. However, this is not very likely because measurements were taken very close to $0^{\circ} \mathrm{C}$, and droplets are thus unlikely to freeze before they reach the measurement volume.

Lastly, the determination of the concentration of secondary ice was based on rather rough assumptions; e.g., small ice crystals, which could not be classified, were expected to be plates, and the growth time was determined for specific environmental conditions, which in reality changed with time and position inside the measurement volume. Apart from this, splinters were assumed to have a specific size, while they could vary in reality. Moreover, only splinters which were small enough to grow into plates were considered to be secondary ice in this study.

\subsection{Other case studies with similar observations}

Several other studies observed an increase in the concentration of small ice crystals in the presence of large supercooled drops in clouds (e.g., Stith et al., 2004; Lawson et al., 2015; Keppas et al., 2017; Korolev et al., 2020; Lloyd et al., 2020). Updrafts were made responsible for the origin of these large droplets in all of the studies. The measurements were taken mostly at temperatures lower than during our case study, where newly formed ice crystals grow into columns. The recirculation process through the melting layer described above (Fig. 7) is therefore also expected to play a role for droplet fragmentation in higher regions of the cloud if the updrafts are strong enough to lift drizzle drops high enough until they freeze. Besides droplet fragmentation, the rime-splintering process is expected to be active in the temperature regime between -3 and $-8^{\circ} \mathrm{C}$, which makes the assignment of the observed secondary ICNC to a specific process more difficult. However, images of deformed frozen drops in all of the abovementioned studies are strong evidence that droplet fragmentation was active and should be accounted for besides the rime-splintering process.

\section{Summary}

On 22 February 2019, wind from the northwest pushed air masses up a mountain slope, where measurements were taken just above the melting layer on a gondola (see Fig. 3). The measurements showed relatively constant conditions during the measurement period of $2 \mathrm{~h}$ (Fig. 6), with a CDNC of about $160 \mathrm{~cm}^{-3}$ and an ICNC of about $6 \mathrm{~L}^{-1}$, which exceeded the measured INPC by several orders of magnitude. The majority of the observed small ice crystals $(L<93 \mu \mathrm{m})$ were identified as plates (Fig. 5). As this is the preferred ice crystal habit at the temperatures in the measurement volume $\left(T>-3^{\circ} \mathrm{C}\right)$, ice crystals smaller than $93 \mu \mathrm{m}$ are assumed to have newly formed in the same environmental conditions. At such warm temperatures, primary-ice nucleation can be neglected, and the concentration of small plates most likely emerged from SIP.

Remarkable was the observation of relatively large droplets between 40 and $380 \mu \mathrm{m}$ at a concentration of $0.3 \mathrm{~L}^{-1} \pm 0.1 \mathrm{~L}^{-1}$ above the melting layer. The appearance of cloud droplets larger than about $40 \mu \mathrm{m}$ is often connected to SIP by droplet fragmentation (Korolev et al., 2020). The rime-splintering process and other SIP processes are not expected to be active and are thus excluded from consideration, and only a small contribution by collisional breakup is assumed, leaving droplet fragmentation as the mainly responsible secondary-ice process. A recirculation theory proposed by Korolev et al. (2020) can explain these observations and can in general be applied to mountainous regions when a melting layer is present, and sufficiently large updrafts are produced on the windward side by the local topography. Aged ice crystals fall through the melting layer as precipitation and melt into drizzle drops. If sufficiently large updrafts are present, these drops are blown up a mountain slope and lifted through the melting layer, and they refreeze if they collide with aged ice crystals. Due to the pressure build-up during freezing, they will fragment and create secondary-ice crystals, which again can initiate the freezing of another drizzle drop (see schematic in Fig. 7). The secondary-ice crystals will be transported to higher altitudes, where they influence the cloud microphysics and subsequently the radiation budget, the lifetime, and the precipitation pattern of the cloud.

A parametrization was introduced in Sect. 4.3 for the generation of secondary-ice particles by droplet fragmentation at temperatures close to $0^{\circ} \mathrm{C}$, when primary-ice nucleation is basically absent (Eq. 6). Based on limited available measurements of previous laboratory studies, it is assumed that the number of splinters produced per droplet is linearly correlated with their diameter and that a droplet of $200 \mu \mathrm{m}$ produces 18 splinters on average when it fragments. Applying the presented parametrization to our measurements could not explain the estimated concentration of secondary ice, and the number of splinters produced per fragmenting droplet has to be higher; i.e., a droplet of $200 \mu \mathrm{m}$ in diameter has to produce $99 \pm 62$ splinters upon fragmentation. This num- 
ber can be reduced to $44 \pm 26$ if we assume that all droplets larger than $40 \mu \mathrm{m}$ fragment when they freeze. This assumption may be reasonable when strong wind speeds or turbulence are present. In either case, the application shows that droplets smaller than about $100 \mu \mathrm{m}$ are negligible for SIP by droplet fragmentation. However, these results critically depend on a single large droplet next to other rather crude assumptions and should be considered with caution. Therefore, the parametrization should be implemented in a model and tested on other case studies, which observed high concentrations of small ice crystals in clouds with temperatures close to $0^{\circ} \mathrm{C}$. The implementation can improve the prediction of the ICNC in mountainous regions, where orographically forced updrafts through a melting layer are observed. A better prediction of the ICNC can improve the determination of the optical properties and the lifetime of clouds as well as precipitation formation from clouds containing ice (e.g., Lohmann, 2002; Henneberg et al., 2017).

Code and data availability. The data used in this study are available at https://doi.org/10.5281/zenodo.4534382 (Lauber et al., 2021a) or referenced herein. The software to reproduce the figures and for calculations done for this study is available at https://doi.org/10.5281/zenodo.4534536 (Lauber et al., 2021b).

Author contributions. AL analyzed and interpreted the data, created the figures, and wrote the manuscript with contributions from JH, CM, FR, JTP, JW, MH, and UL. AL, JH, CM, FR, JTP, and JW performed the measurements on the Gotschnabahn. MH operated the radar wind profiler and the ceilometer and processed the data.

Competing interests. The authors declare that they have no conflict of interest.

Acknowledgements. The authors would like to thank the whole RACLETS team for the installation and maintenance of the measurement setup as well as many fruitful scientific discussions. We would especially like to thank Michael Lehning (WSL/SLF, EPFL) and his whole team for their effort in supporting and realizing the RACLETS campaign. A special thanks also goes to the Davos Klosters Bergbahnen AG and the staff of the Gotschnabahn, especially the technical managers Andrea Margadant and the managing director Markus Good, for the permission to take measurements on one of their gondolas as well as the on-site support. We would also like thank Paul Fopp for providing his land for the remote-sensing measurements. We would like to thank Alexander Beck for his support in the organization of the RACLETS campaign. We thank the Swiss Federal Office of Meteorology and Climatology MeteoSwiss for providing us with meteorological measurements and installing the ceilometer and the weather station in Klosters as well as the radar wind profiler in Wolfgang. We would also like to thank the Grischa paragliding club for providing us with meteorological mea- surements from their Holfuy station at Gotschnagrat. We would like to thank Hannes Griesche for supplying us with turbulence data, Patric Seifert (TROPOS, Germany) for discussing their measurements, and Benjamin Walter for providing us with data from the snow drift station at Gotschnagrat, and we would like to thank Pila Bossmann (https://wetterboss.com/, last access: 22 September 2020) for discussing the general weather situation. We would also like to thank our reviewers Alexei Korolev and Andrew Heymsfield for their constructive and helpful feedback.

Financial support. This research has been supported by the Swiss National Science Foundation (grant nos. 200021_175824 and 200021_169620).

Review statement. This paper was edited by Daniel Knopf and reviewed by Alexei Korolev and Andrew Heymsfield.

\section{References}

Bader, M. J. and Roach, W. T.: Orographic rainfall in warm sectors of depressions, Q. J. Roy. Meteorol. Soc., 103, 269-280, https://doi.org/10.1002/qj.49710343605, 1977.

Bailey, M. P. and Hallett, J.: A Comprehensive Habit Diagram for Atmospheric Ice Crystals: Confirmation from the Laboratory, AIRS II, and Other Field Studies, J. Atmos. Sci., 66, 2888-2899, https://doi.org/10.1175/2009JAS2883.1, 2009.

Beck, A.: Observing the Microstructure of Orographic Clouds with HoloGondel, PhD thesis, ETH Zurich, Zurich, https://doi.org/10.3929/ethz-b-000250847, 2017.

Beck, A., Henneberger, J., Schöpfer, S., Fugal, J., and Lohmann, U.: HoloGondel: in situ cloud observations on a cable car in the Swiss Alps using a holographic imager, Atmos. Meas. Tech., 10, 459-476, https://doi.org/10.5194/amt-10-459-2017, 2017.

Beck, A., Henneberger, J., Fugal, J. P., David, R. O., Lacher, L., and Lohmann, U.: Impact of surface and near-surface processes on ice crystal concentrations measured at mountaintop research stations, Atmos. Chem. Phys., 18, 8909-8927, https://doi.org/10.5194/acp-18-8909-2018, 2018.

Beheng, K. D.: Microphysical Properties of Glaciating Cumulus Clouds: Comparison of Measurements With A Numerical Simulation, Q. J. Roy. Meteorol. Soc., 113, 1377-1382, https://doi.org/10.1002/qj.49711347815, 1987.

Bergeron, T.: On the physics of clouds and precipitation, in: roc. 5th Assembly UGGI, Lisbon, Portugal, 156-180, 1935.

Borque, P., Luke, E., and Kollias, P.: On the unified estimation of turbulence eddy dissipation rate using Doppler cloud radars and lidars: Radar and Lidar Turbulence Estimation, J. Geophys. Res.-Atmos., 121, 5972-5989, https://doi.org/10.1002/qj.49712253605, 2016.

Bower, K. N., Moss, S. J., Johnson, D. W., Choularton, T. W., Latham, J., Brown, P. R. A., Blyth, A. M., and Cardwell, J.: A parametrization of the ice water content observed in frontal and convective clouds, Q. J. Roy. Meteorol. Soc., 122, 1815-1844, https://doi.org/10.1002/qj.49712253605, 1996. 
Braham, R. R.: What is the Role of Ice in Summer Rain-Showers?, J. Atmos. Sci., 21, 640-645, https://doi.org/10.1175/15200469(1964)021<0640:WITROI>2.0.CO;2, 1964.

Chisnell, R. F. and Latham, J.: A stochastic model of ice particle multiplication by drop splintering, Q. J. Roy. Meteorol. Soc., 100, 296-308, https://doi.org/10.1002/qj.49710042504, 1974.

Crawford, I., Bower, K. N., Choularton, T. W., Dearden, C., Crosier, J., Westbrook, C., Capes, G., Coe, H., Connolly, P. J., Dorsey, J. R., Gallagher, M. W., Williams, P., Trembath, J., Cui, Z., and Blyth, A.: Ice formation and development in aged, wintertime cumulus over the UK: observations and modelling, Atmos. Chem. Phys., 12, 4963-4985, https://doi.org/10.5194/acp12-4963-2012, 2012.

David, R. O., Cascajo-Castresana, M., Brennan, K. P., Rösch, M., Els, N., Werz, J., Weichlinger, V., Boynton, L. S., Bogler, S., Borduas-Dedekind, N., Marcolli, C., and Kanji, Z. A.: Development of the DRoplet Ice Nuclei Counter Zurich (DRINCZ): validation and application to field-collected snow samples, Atmos. Meas. Tech., 12, 6865-6888, https://doi.org/10.5194/amt12-6865-2019, 2019.

Dong, Y. Y. and Hallett, J.: Droplet accretion during rime growth and the formation of secondary ice crystals, Q. J. Roy. Meteorol. Soc., 115, 127-142, https://doi.org/10.1002/qj.49711548507, 1989.

Field, P. R., Lawson, R. P., Brown, P. R. A., Lloyd, G., Westbrook, C., Moisseev, D., Miltenberger, A., Nenes, A., Blyth, A., Choularton, T., Connolly, P., Buehl, J., Crosier, J., Cui, Z., Dearden, C., DeMott, P., Flossmann, A., Heymsfield, A., Huang, Y., Kalesse, H., Kanji, Z. A., Korolev, A., Kirchgaessner, A., LasherTrapp, S., Leisner, T., McFarquhar, G., Phillips, V., Stith, J., and Sullivan, S.: Secondary Ice Production: Current State of the Science and Recommendations for the Future, Meteorol. Monogr., 58, 7.1-7.20, https://doi.org/10.1175/AMSMONOGRAPHS-D16-0014.1, 2017.

Findeisen, W.: Kolloid-meteorologische Vorgänge bei Neiderschlagsbildung, Meteorol. Z., 55, 121-133, 1938.

Fukuta, N. and Takahashi, T.: The Growth of Atmospheric Ice Crystals: A Summary of Findings in Vertical Supercooled Cloud Tunnel Studies, J. Atmos. Sci., 56, 1963-1979, https://doi.org/10.1175/15200469(1999)056<1963:TGOAIC>2.0.CO;2, 1999.

Fundel, F., Walser, A., Liniger, M. A., Frei, C., and Appenzeller, C.: Calibrated Precipitation Forecasts for a Limited-Area Ensemble Forecast System Using Reforecasts, Mon. Weather Rev., 138, 176-189, https://doi.org/10.1175/2009MWR2977.1, 2010.

Georgakaki, P., Bougiatioti, A., Wieder, J., Mignani, C., Ramelli, F., Kanji, Z. A., Henneberger, J., Hervo, M., Berne, A., Lohmann, U., and Nenes, A.: On the drivers of droplet variability in Alpine mixed-phase clouds, Atmos. Chem. Phys. Discuss. [preprint], https://doi.org/10.5194/acp-2020-1036, in review, 2020.

Görsdorf, U., Lehmann, V., Bauer-Pfundstein, M., Peters, G., Vavriv, D., Vinogradov, V., and Volkov, V.: A 35-GHz Polarimetric Doppler Radar for Long-Term Observations of Cloud Parameters - Description of System and Data Processing, J. Atmos. Ocean. Tech., 32, 675-690, https://doi.org/10.1175/JTECH-D14-00066.1, 2015.

Gowan, T. M., Steenburgh, W. J., and Schwartz, C. S.: Validation of Mountain Precipitation Forecasts from the ConvectionPermitting NCAR Ensemble and Operational Forecast Systems over the Western United States, Weather Forecast., 33, 739-765, https://doi.org/10.1175/WAF-D-17-0144.1, 2018.

Griesche, H. J., Seifert, P., Ansmann, A., Baars, H., Barrientos Velasco, C., Bühl, J., Engelmann, R., Radenz, M., Zhenping, Y., and Macke, A.: Application of the shipborne remote sensing supersite OCEANET for profiling of Arctic aerosols and clouds during Polarstern cruise PS106, Atmos. Meas. Tech., 13, 53355358, https://doi.org/10.5194/amt-13-5335-2020, 2020.

Griggs, D. J. and Choularton, T. W.: Freezing modes of riming droplets with application to ice splinter production, Q. J. Roy. Meteorol. Soc., 109, 243-253, https://doi.org/10.1002/qj.49710945912, 1983.

Hallett, J. and Mossop, S. C.: Production of secondary ice particles during the riming process, Nature, 249, 26-28, https://doi.org/10.1038/249026a0, 1974.

Harris-Hobbs, R. L. and Cooper, W. A.: Field Evidence Supporting Quantitative Predictions of Secondary Ice Production Rates, J. Atmos. Sci., 44, 1071-1082, https://doi.org/10.1175/15200469(1987)044<1071:FESQPO>2.0.CO;2, 1987.

Henneberg, O., Henneberger, J., and Lohmann, U.: Formation and Development of Orographic Mixed-Phase Clouds, J. Atmos. Sci., 74, 3703-3724, https://doi.org/10.1175/JAS-D-16-0348.1, 2017.

Henneberger, J., Fugal, J. P., Stetzer, O., and Lohmann, U.: HOLIMO II: a digital holographic instrument for groundbased in situ observations of microphysical properties of mixed-phase clouds, Atmos. Meas. Tech., 6, 2975-2987, https://doi.org/10.5194/amt-6-2975-2013, 2013.

Hervo, M.: Weather Station Klosters, EnviDat [data set], https://doi.org/10.16904/envidat.129, 2019.

Hervo, M.: Ceilometer Klosters, EnviDat [data set], https://doi.org/10.16904/envidat.127, 2020a.

Hervo, M.: RADAR Wind profiler Davos Wolfgang, EnviDat [data set], https://doi.org/10.16904/envidat.130, 2020b.

Hobbs, P. V. and Rangno, A. L.: Ice Particle Concentrations in Clouds, J. Atmos. Sci., 42, 2523-2549, https://doi.org/10.1175/15200469(1985)042<2523:IPCIC>2.0.CO;2, 1985.

Hobbs, P. V. and Rangno, A. L.: Rapid Development of High Ice Particle Concentrations in Small Polar Maritime Cumuliform Clouds, J. Atmos. Sci., 47, 2710-2722, https://doi.org/10.1175/15200469(1990)047<2710:RDOHIP>2.0.CO;2, 1990.

Jiusto, J. E. and Weickmann, H. K.: types of snowfall, B. Am. Meteorol. Soc., 54, 1148-1162, https://doi.org/10.1175/15200477(1973)054<1148:TOS>2.0.CO;2, 1973.

Keinert, A., Spannagel, D., Leisner, T., and Kiselev, A.: Secondary Ice Production upon Freezing of Freely Falling Drizzle Droplets, J. Atmos. Sci., 77, 2959-2967, https://doi.org/10.1175/JAS-D20-0081.1, 2020.

Keppas, S. C., Crosier, J., Choularton, T. W., and Bower, K. N.: Ice lollies: An ice particle generated in supercooled conveyor belts, Geophys. Res. Lett., 44, 5222-5230, https://doi.org/10.1002/2017GL073441, 2017.

King, W. D. and Fletcher, N. H.: Thermal Shock as an Ice Multiplication Mechanism. Part I. Theory, J. Atmos. Sci., 33, 85-96, https://doi.org/10.1175/15200469(1976)033<0085:TSAAIM>2.0.CO;2, 1976.

Kleinheins, J., Kiselev, A., Keinert, A., and Leisner, T.: Thermal imaging of a shattering freezing water droplet, in: EGU 
General Assembly 2020, https://doi.org/10.5194/egusphereegu2020-2889, 2020.

Koenig, L. R.: The Glaciating Behavior of Small Cumulonimbus Clouds, J. Atmos. Sci., 20, 29-47, https://doi.org/10.1175/15200469(1963)020<0029:TGBOSC $>2.0 . C O ; 2,1963$.

Kolomeychuk, R. J., McKay, D. C., and Iribarne, J. V.: The Fragmentation and Electrification of Freezing Drops, J. Atmos. Sci., 32, 974-979, https://doi.org/10.1175/15200469(1975)032<0974:TFAEOF>2.0.CO;2, 1975.

Korolev, A.: Limitations of the Wegener-Bergeron-Findeisen Mechanism in the Evolution of Mixed-Phase Clouds, J. Atmos. Sci., 64, 3372-3375, https://doi.org/10.1175/JAS4035.1, 2007.

Korolev, A. and Isaac, G. A.: Relative Humidity in Liquid, Mixed-Phase, and Ice Clouds, J. Atmos. Sci., 63, 2865-2880, https://doi.org/10.1175/JAS3784.1, 2006.

Korolev, A. and Leisner, T.: Review of experimental studies of secondary ice production, Atmos.Chem. Phys., 20, 11767-11797, https://doi.org/10.5194/acp-20-11767-2020, 2020.

Korolev, A., Heckman, I., Wolde, M., Ackerman, A. S., Fridlind, A. M., Ladino, L. A., Lawson, R. P., Milbrandt, J., and Williams, E.: A new look at the environmental conditions favorable to secondary ice production, Atmos. Chem. Phys., 20, 1391-1429, https://doi.org/10.5194/acp-20-1391-2020, 2020.

Ladino, L. A., Korolev, A., Heckman, I., Wolde, M., Fridlind, A. M., and Ackerman, A. S.: On the role of ice-nucleating aerosol in the formation of ice particles in tropical mesoscale convective systems, Geophys. Res. Lett., 44, 1574-1582, https://doi.org/10.1002/2016GL072455, 2017.

Lasher-Trapp, S., Leon, D. C., DeMott, P. J., Villanueva-Birriel, C. M., Johnson, A. V., Moser, D. H., Tully, C. S., and Wu, W.: A Multisensor Investigation of Rime Splintering in Tropical Maritime Cumuli, J. Atmos. Sci., 73, 2547-2564, https://doi.org/10.1175/JAS-D-15-0285.1, 2016.

Lauber, A., Kiselev, A., Pander, T., Handmann, P., and Leisner, T.: Secondary Ice Formation during Freezing of Levitated Droplets, J. Atmos. Sci., 75, 2815-2826, https://doi.org/10.1175/JAS-D18-0052.1, 2018.

Lauber, A., Baars, H., Bühl, J., Engelmann, R., Henneberger, J., Hervo, M., Mignani, C., Pasquier, J. T., Radenz, M., Ramelli, F., Seifert, P., and Wieder, J.: Data for "Continuous secondary ice production initiated by updrafts through the melting layer in mountainous regions", Zenodo [data set], https://doi.org/10.5281/zenodo.4534382, 2021a.

Lauber, A., Ramelli, F., and Hervo, M.: AnnikaLau/SIP_initiated_by_melting_layer: Software for the paper "Continuous secondary ice production initiated by updrafts through the melting layer in mountainous regions" by Lauber et al. 2021 ACP, v1.0.0, Zenodo [code], https://doi.org/10.5281/zenodo.4534536, 2021b.

Lawson, P., Gurganus, C., Woods, S., and Bruintjes, R.: Aircraft Observations of Cumulus Microphysics Ranging from the Tropics to Midlatitudes: Implications for a "New" Secondary Ice Process, J. Atmos. Sci., 74, 2899-2920, https://doi.org/10.1175/JASD-17-0033.1, 2017.

Lawson, R. P., Woods, S., and Morrison, H.: The Microphysics of Ice and Precipitation Development in Tropical Cumulus Clouds, J. Atmos. Sci., 72, 2429-2445, https://doi.org/10.1175/JAS-D14-0274.1, 2015.
Libbrecht, K. G.: The physics of snow crystals, Rep. Progr. Phys., 68, 855-895, https://doi.org/10.1088/0034-4885/68/4/r03, 2005.

Lloyd, G., Choularton, T., Bower, K., Crosier, J., Gallagher, M., Flynn, M., Dorsey, J., Liu, D., Taylor, J. W., Schlenczek, O., Fugal, J., Borrmann, S., Cotton, R., Field, P., and Blyth, A.: Small ice particles at slightly supercooled temperatures in tropical maritime convection, Atmos. Chem. Phys., 20, 3895-3904, https://doi.org/10.5194/acp-20-3895-2020, 2020.

Locatelli, J. D. and Hobbs, P. V.: Fall speeds and masses of solid precipitation particles, J. Geophys. Res., 79, 2185-2197, https://doi.org/10.1029/JC079i015p02185, 1974.

Lohmann, U.: Possible Aerosol Effects on Ice Clouds via Contact Nucleation, J. Atmos. Sci., 59, 647-656, https://doi.org/10.1175/15200469(2001)059<0647:PAEOIC>2.0.CO;2, 2002.

Lohmann, U., Henneberger, J., Henneberg, O., Fugal, J. P., Bühl, J., and Kanji, Z. A.: Persistence of orographic mixed-phase clouds, Geophys. Res. Lett., 43, 10512-10519, https://doi.org/10.1002/2016GL071036, 2016.

Mignani, C., Wieder, J., Sprenger, M. A., Kanji, Z. A., Henneberger, J., Alewell, C., and Conen, F.: Towards parameterising atmospheric concentrations of ice-nucleating particles active at moderate supercooling, Atmos. Chem. Phys., 21, 657-664, https://doi.org/10.5194/acp-21-657-2021, 2021.

Mitchell, D. L., Zhang, R., and Pitter, R. L.: MassDimensional Relationships for Ice Particles and the Influence of Riming on Snowfall Rates, J. Appl. Meteorol., 29, 153-163, https://doi.org/10.1175/15200450(1990)029<0153:MDRFIP>2.0.CO;2, 1990.

Mossop, S. C., Ono, A., and Wishart, E. R.: Ice particles in maritime clouds near Tasmania, Q. J. Roy. Meteorol. Soc., 96, 487-508, https://doi.org/10.1002/qj.49709640910, 1970.

Mossop, S. C., Cottis, R. E., and Bartlett, B. M.: Ice crystal concentrations in cumulus and stratocumulus clouds, Q. J. Roy. Meteorol. Soc., 98, 105-123, https://doi.org/10.1002/qj.49709841509, 1972.

Mülmenstädt, J., Sourdeval, O., Delanoë, J., and Quaas, J.: Frequency of occurrence of rain from liquid-, mixed-, and ice-phase clouds derived from A-Train satellite retrievals, Geophys. Res. Lett., 42, 6502-6509, https://doi.org/10.1002/2015GL064604, 2015.

Ono, A.: Some Aspects of the Natural Glaciation Processes in Relatively Warm Maritime Clouds, J. Meteorol. Soc. Jpn. Ser. II, 49A 845-858, https://doi.org/10.2151/jmsj1965.49A.0_845, 1971.

Ono, A.: Evidence on the nature of ice crystal multiplication processes in natural cloud, Journal de rechereches atmosphériques, 6, 399-4080, 1972.

Oraltay, R. and Hallett, J.: Evaporation and melting of ice crystals: A laboratory study, Atmos. Res., 24, 169-189, https://doi.org/10.1016/0169-8095(89)90044-6, 1989.

Phillips, V. T. J., Blyth, A. M., Brown, P. R. A., Choularton, T. W., and Latham, J.: The glaciation of a cumulus cloud over New Mexico, Q. J. Roy. Meteorol. Soc., 127, 1513-1534, https://doi.org/10.1002/qj.49712757503, 2001.

Phillips, V. T. J., Yano, J.-I., and Khain, A.: Ice Multiplication by Breakup in Ice-Ice Collisions. Part I: Theoretical Formulation, J. Atmos. Sci., 74, 1705-1719, https://doi.org/10.1175/JAS-D-160224.1, 2017. 
Pruppacher, H. and Klett, J.: Microphysics of Clouds and Precipitation, Springer, Dordrecht, https://doi.org/10.1007/978-0-30648100-0, 2010.

Ramelli, F., Henneberger, J., David, R. O., Bühl, J., Radenz, M., Seifert, P., Wieder, J., Lauber, A., Pasquier, J. T., Engelmann, R., Mignani, C., Hervo, M., and Lohmann, U.: Microphysical investigation of the seeder and feeder region of an Alpine mixed-phase cloud, Atmos. Chem. Phys. Discuss. [preprint], https://doi.org/10.5194/acp-2020-772, in review, 2020a.

Ramelli, F., Henneberger, J., David, R. O., Lauber, A., Pasquier, J. T., Wieder, J., Bühl, J., Seifert, P., Engelmann, R., Hervo, M., and Lohmann, U.: Influence of low-level blocking and turbulence on the microphysics of a mixed-phase cloud in an inner-Alpine valley, Atmos. Chem. Phys. Discuss. [preprint], https://doi.org/10.5194/acp-2020-774, in review, 2020b.

Rangno, A. L.: Fragmentation of Freezing Drops in Shallow Maritime Frontal Clouds, J. Atmos. Sci., 65, 1455-1466, https://doi.org/10.1175/2007JAS2295.1, 2008.

Roe, G. H.: Orographic precipitation, Annu. Rev. Earth Planet. Sci., 33, 645-671, 2005.

Rogers, R. R. and Yau, M. K.: A Short Course in Cloud Physics, Butterworth-Heinemann, Oxford, 1989.

Sassen, K., Campbell, J. R., Zhu, J., Kollias, P., Shupe, M., and Williams, C.: Lidar and Triple-Wavelength Doppler Radar Measurements of the Melting Layer: A Revised Model for Darkand Brightband Phenomena, J. Appl. Meteorol., 44, 301-312, https://doi.org/10.1175/JAM-2197.1, 2005.

Schwarzenboeck, A., Shcherbakov, V., Lefevre, R., Gayet, J.F., Pointin, Y., and Duroure, C.: Indications for stellar-crystal fragmentation in Arctic clouds, Atmos. Res., 92, 220-228, https://doi.org/10.1016/j.atmosres.2008.10.002, 2009.

Scott, B. C. and Hobbs, P. V.: A Theoretical Study of the Evolution of Mixed-Phase Cumulus Clouds, J. Atmos. Sci., 34, 812-826, https://doi.org/10.1175/15200469(1977)034<0812:ATSOTE>2.0.CO;2, 1977.

Siebert, H., Franke, H., Lehmann, K., Maser, R., Saw, E. W., Schell, D., Shaw, R. A., and Wendisch, M.: Probing Finescale Dynamics and Microphysics of Clouds with Helicopter-Borne Measurements, B. Am. Meteorol.Soc., 87, 1727-1738, https://doi.org/10.1175/BAMS-87-12-1727, 2006.

Sotiropoulou, G., Ickes, L., Nenes, A., and Ekman, A. M. L.: Ice multiplication from ice-ice collisions in the high Arctic: sensitivity to ice habit, rimed fraction and the spectral representation of the colliding particles, Atmos. Chem. Phys. Discuss. [preprint], https://doi.org/10.5194/acp-2020-786, in review, 2020a.

Sotiropoulou, G., Sullivan, S., Savre, J., Lloyd, G., Lachlan-Cope, T., Ekman, A. M. L., and Nenes, A.: The impact of secondary ice production on Arctic stratocumulus, Atmos. Chem. Phys., 20, 1301-1316, https://doi.org/10.5194/acp-20-1301-2020, 2020 b.

Sotiropoulou, G., Vignon, E., Young, G., Morrison, H., O’Shea, S. J., Lachlan-Cope, T., Berne, A., and Nenes, A.: Secondary ice production in summer clouds over the Antarctic coast: an underappreciated process in atmospheric models, Atmos. Chem. Phys., 21, 755-771, https://doi.org/10.5194/acp-21-755-2021, 2021.
Stith, J. L., Haggerty, J. A., Heymsfield, A., and Grainger, C. A.: Microphysical Characteristics of Tropical Updrafts in Clean Conditions, J. Appl. Meteorol., 43, 779-794, https://doi.org/10.1175/2104.1, 2004.

Stopelli, E., Conen, F., Zimmermann, L., Alewell, C., and Morris, C. E.: Freezing nucleation apparatus puts new slant on study of biological ice nucleators in precipitation, Atmos. Meas. Tech., 7, 129-134, https://doi.org/10.5194/amt-7-129-2014, 2014.

Sullivan, S. C., Barthlott, C., Crosier, J., Zhukov, I., Nenes, A., and Hoose, C.: The effect of secondary ice production parameterization on the simulation of a cold frontal rainband, Atmos. Chem. Phys., 18, 16461-16480, https://doi.org/10.5194/acp-18-164612018, 2018a.

Sullivan, S. C., Hoose, C., Kiselev, A., Leisner, T., and Nenes, A.: Initiation of secondary ice production in clouds, Atmos. Chem. Phys., 18, 1593-1610, https://doi.org/10.5194/acp-181593-2018, 2018 b.

Takahashi, C. and Yamashita, A.: Deformation and Fragmentation of Freezing Water Drops in Free Fall, J. Meteorol. Soc. Jpn. Ser. II, 47, 431-436, https://doi.org/10.2151/jmsj1965.47.6_431, 1969.

Takahashi, T., Nagao, Y., and Kushiyama, Y.: Possible High Ice Particle Production during Graupel-Graupel Collisions, J. Atmos. Sci., 52, 4523-4527, https://doi.org/10.1175/15200469(1995)052<4523:PHIPPD>2.0.CO;2, 1995.

Touloupas, G., Lauber, A., Henneberger, J., Beck, A., and Lucchi, A.: A convolutional neural network for classifying cloud particles recorded by imaging probes, Atmos. Meas. Tech., 13, 2219 2239, https://doi.org/10.5194/amt-13-2219-2020, 2020.

Vali, G.: Quantitative Evaluation of Experimental Results an the Heterogeneous Freezing Nucleation of Supercooled Liquids, J. Atmos. Sci., 28, 402-409, https://doi.org/10.1175/15200469(1971)028<0402:QEOERA>2.0.CO;2, 1971.

Vardiman, L.: The Generation of Secondary Ice Particles in Clouds by Crystal-Crystal Collision, J. Atmos. Sci., 35, 2168-2180, https://doi.org/10.1175/15200469(1978)035<2168:TGOSIP>2.0.CO;2, 1978.

Walter, B. and Huwald, H.: Snow Drift Station - 3D Ultrasonic, EnviDat [data set], https://doi.org/10.16904/envidat.116, 2019.

Walter, B., Huwald, H., Gehring, J., Bühler, Y., and Lehning, M.: Radar measurements of blowing snow off a mountain ridge, The Cryosphere, 14, 1779-1794, https://doi.org/10.5194/tc-14-17792020, 2020.

Wegener, A.: Thermodynamik der Atmosphäre, J. A. Barth, Leipzig, 1911.

Yang, J., Wang, Z., Heymsfield, A. J., DeMott, P. J., Twohy, C. H., Suski, K. J., and Toohey, D. W.: High ice concentration observed in tropical maritime stratiform mixed-phase clouds with top temperatures warmer than $-8{ }^{\circ} \mathrm{C}$, Atmos. Res., 233, 104719 , https://doi.org/10.1016/j.atmosres.2019.104719, 2020.

Yano, J.-I. and Phillips, V. T. J.: Ice-Ice Collisions: An Ice Multiplication Process in Atmospheric Clouds, J. Atmos. Sci., 68, 322-333, https://doi.org/10.1175/2010JAS3607.1, 2011. 